University of Windsor

Scholarship at UWindsor

$1-1-2005$

\title{
Re-defining fusion in lesbian relationships: Relating attachment, social support, and outness to intrusiveness and closeness- caregiving.
}

Salma Ackbar

University of Windsor

Follow this and additional works at: https://scholar.uwindsor.ca/etd

\section{Recommended Citation}

Ackbar, Salma, "Re-defining fusion in lesbian relationships: Relating attachment, social support, and outness to intrusiveness and closeness-caregiving." (2005). Electronic Theses and Dissertations. 6937. https://scholar.uwindsor.ca/etd/6937

This online database contains the full-text of PhD dissertations and Masters' theses of University of Windsor students from 1954 forward. These documents are made available for personal study and research purposes only, in accordance with the Canadian Copyright Act and the Creative Commons license-CC BY-NC-ND (Attribution, Non-Commercial, No Derivative Works). Under this license, works must always be attributed to the copyright holder (original author), cannot be used for any commercial purposes, and may not be altered. Any other use would require the permission of the copyright holder. Students may inquire about withdrawing their dissertation and/or thesis from this database. For additional inquiries, please contact the repository administrator via email (scholarship@uwindsor.ca) or by telephone at 519-253-3000ext. 3208. 
Re-defining Fusion in Lesbian Relationships: Relating Attachment, Social

Support, and Outness to Intrusiveness and Closeness-caregiving

by

Salma Ackbar

\begin{abstract}
A Thesis
Submitted to the Faculty of Graduate Studies and Research

through the Department of Psychology

in Partial Fulfillment of the Requirements for the Degree of Master of Arts at the University of Windsor
\end{abstract}

\author{
Windsor, Ontario, Canada
}

2005

(C) 2005 Salma Ackbar 


$\begin{array}{ll}\begin{array}{l}\text { Library and } \\ \text { Archives Canada }\end{array} & \begin{array}{l}\text { Bibliothèque et } \\ \text { Archives Canada }\end{array} \\ \begin{array}{l}\text { Published Heritage } \\ \text { Branch }\end{array} & \begin{array}{l}\text { Direction du } \\ \text { Patrimoine de l'édition }\end{array} \\ \begin{array}{l}\text { 395 Wellington Street } \\ \text { Ottawa ON K1A ON4 }\end{array} & \begin{array}{l}\text { 395, rue Wellington } \\ \text { Ottawa ON K1A ON4 } \\ \text { Canada }\end{array}\end{array}$

Your file Votre référence

ISBN: 0-494-09824-4

Our file Notre référence

ISBN: 0-494-09824-4

NOTICE:

The author has granted a nonexclusive license allowing Library and Archives Canada to reproduce, publish, archive, preserve, conserve, communicate to the public by telecommunication or on the Internet, loan, distribute and sell theses worldwide, for commercial or noncommercial purposes, in microform, paper, electronic and/or any other formats.

The author retains copyright ownership and moral rights in this thesis. Neither the thesis nor substantial extracts from it may be printed or otherwise reproduced without the author's permission.
AVIS:

L'auteur a accordé une licence non exclusive permettant à la Bibliothèque et Archives Canada de reproduire, publier, archiver, sauvegarder, conserver, transmettre au public par télécommunication ou par l'Internet, prêter, distribuer et vendre des thèses partout dans le monde, à des fins commerciales ou autres, sur support microforme, papier, électronique et/ou autres formats.

L'auteur conserve la propriété du droit d'auteur et des droits moraux qui protège cette thèse. $\mathrm{Ni}$ la thèse ni des extraits substantiels de celle-ci ne doivent être imprimés ou autrement reproduits sans son autorisation.
In compliance with the Canadian

Privacy Act some supporting forms may have been removed from this thesis.

While these forms may be included in the document page count, their removal does not represent any loss of content from the thesis.
Conformément à la loi canadienne sur la protection de la vie privée, quelques formulaires secondaires ont été enlevés de cette thèse.

Bien que ces formulaires aient inclus dans la pagination, il n'y aura aucun contenu manquant.

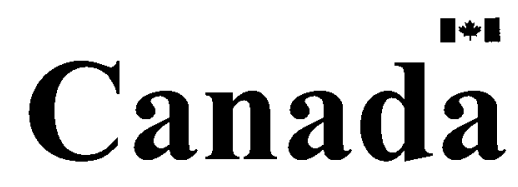


Abstract

Fusion is defined as a state of intense intimacy, which is dysfunctional because it impedes the separate functioning of romantic partners (Karpel, 1976). This traditionally negative view of fusion has pathologized the intimacy patterns of lesbian couples by overlooking the benefits that high levels of closeness could have for lesbian partners. Hence, in this study, fusion was conceptualized as consisting of separate positive (closeness-caregiving) and negative (intrusiveness) dimensions. Moreover, this study extended the literature by examining how adult attachment typology related to dimensions of closeness-caregiving and intrusiveness in lesbian relationships. Participants were 77 lesbians and bisexual women between the ages of 18 and 62 years. Women showed much higher levels of positive fusion than negative fusion in their relationships. Additionally, greater positive fusion strongly predicted greater relationship satisfaction. In general, developmental variables of age and attachment were better predictors of positive and negative fusion than social variables of social support and outness. This research provides more positive conceptualizations of fusion for therapists who work with lesbian couples and has vital implications for existing theories about fusion in lesbian relationships. 


\section{Acknowledgements}

I would like to thank all of those who have supported, encouraged and guided me throughout this academic journey. Special thanks to my research advisor, Dr. Charlene Senn, to whom I am truly grateful. Your generosity, patience and constructive feedback have kept me going throughout the last two years and have been crucial to my success. Special thanks also to Division 44 of the American Psychological Association for awarding me the 2005 Malyon-Smith Scholarship which has helped to fund this research.

To Dr. Roseanne Menna and Dr. Alan Sears, thank you for being on my committee and for helping to improve the quality of my research. Thank you to Dr. Dennis Jackson for your statistical advice. To Barb Zakoor, I give many thanks. Many thanks also to the members of my research group (Sherry, Surbhi, Charmaine, and Kristin) for your ideas and feedback, and for assisting with my data collection.

To all of the women who participated in this research, thank you for offering your time and for sharing your personal information with me. Without you this thesis would never have been possible. Finally, I give thanks to my partner, Justine. Justine, you have stood by me throughout the best and worst times of this journey. I can never thank you enough for the endless love, kindness and support you offer me. 
ABSTRACT

ACKNOWLEDGEMENTS

LIST OF TABLES Vii

CHAPTER

I. INTRODUCTION

Definitions of Fusion $\quad 2$

Origin of Fusion in Family Enmeshment 2

Fusion in Lesbian Relationships $\quad 4$

Theories for Fusion in Lesbian Relationships $\quad 8$

Re-defining Fusion $\quad 11$

Empirical Research on Fusion $\quad 13$

Age 15

$\begin{array}{ll}\text { Attachment Style } & 16\end{array}$

Social Support $\quad 21$

Outness 23

Fusion as Intrusiveness and Closeness-caregiving 26

$\begin{array}{ll}\text { Measurement Issues } & 28\end{array}$

$\begin{array}{ll}\text { Research questions } & 28\end{array}$

$\begin{array}{ll}\text { Hypotheses } & 29\end{array}$

II. METHOD

Participants 33

$\begin{array}{ll}\text { Procedure } & 37\end{array}$

$\begin{array}{ll}\text { Measures } & 38\end{array}$

III. RESULTS

Preliminary Analyses $\quad 46$

Main Analyses $\quad 47$

$\begin{array}{ll}\text { Descriptive Statistics and Inter-Correlations } & 47\end{array}$ 
Predicting Intrusiveness $\quad 51$

Predicting Closeness-caregiving 54

Predicting Relationship Satisfaction $\quad 57$

$\begin{array}{ll}\text { Post-hoc Analyses } & 57\end{array}$

IV. DISCUSSION

Theoretical Implications $\quad 68$

Clinical Implications $\quad 72$

$\begin{array}{ll}\text { Limitations } & 74\end{array}$

$\begin{array}{ll}\text { Directions for Future Research } & 77\end{array}$

$\begin{array}{lr}\text { REFERENCES } & 81\end{array}$

APPENDICES

Appendix A: Bartholomew's Typology of Adult Attachment 91

Appendix B: Flyer Advertisement $\quad 92$

Appendix C: Email Recruitment Script 93

Appendix D: Cover Sheet 94

Appendix E: Letter of Information 95

Appendix F: List of Community Resources for Lesbian and Bisexual Women $\quad 97$

Appendix G: California Inventory for Family Assessment 101

Appendix H: Experiences In Close Relationships Inventory 102

Appendix I: Multidimensional Scale of Perceived Social Support 104

Appendix J: Network Sector Closeting Measure 105

Appendix K: Relationship Assessment Scale 107

Appendix L: Demographic Information Questionnaire 108

VITA AUCTORIS 112 
Table 1 Summary of Demographic Characteristics of Participants and their Partners

Table 2 Intercorrelations among Subscales of the Network-sector Closeting Measure

Table 3 Means, Standard Deviations, and Range of Responses for Predictor and Dependent Variables

Table 4 Intercorrelations among Predictor and Dependent Variables

Table 5 Hierarchical Regression Analysis Summary for Age, Attachment, Social Support and Outness Variables Predicting Intrusiveness $(\mathrm{N}=77)$

Table 6 Hierarchical Regression Analysis Summary for Attachment, Social Support, and Outness Variables Predicting

Closeness-caregiving $(\mathrm{N}=77)$ 


\section{CHAPTER I}

Introduction

Every day, lesbians and bisexual women are confronted with a multitude of negative judgments about their lives and their romantic relationships with women. For instance, it is thought that their romantic relationships are superficial and will not last, that they cannot raise healthy children and families, and that their values are immoral.

Unfortunately in the past, through the emergence of conversion therapies, organized psychology has played a leading role in the pathologizing of homosexuality (Brown, 1996). Although more recently, psychologists have tried to counter such homophobia with research showing that outcomes for romantic and family relationships of lesbian couples are no more negative than for heterosexual couples (Brehm, 1992; Patterson, 1994), many misperceptions about same-sex relationships persist among psychologists today.

One such misperception concerns levels of closeness in lesbian relationships. Lesbian relationships have often been labelled as "fused" because they tend to be characterized by very high levels of closeness (Zacks, Green \& Marrow, 1988). Because early psychological literature has always regarded fusion as dysfunctional, high levels of intimacy between lesbian partners have come to be labelled as unhealthy (Krestan \& Bepko, 1980). However, traditional conceptualizations of fusion have tended to blend positive and negative types of closeness (Green \& Werner, 1996) and as such, have overlooked the benefits of high levels of closeness for lesbian partners. Thus, the current study proposed a theoretical re-definition of fusion, in which positive and negative dimensions of fusion were distinguished and measured separately. Furthermore, this study 
examined how specific developmental and social factors influenced women's tendencies to show positive or negative patterns of fusion in their lesbian relationships.

\section{Definitions of Fusion}

In the psychological literature, fusion has been traditionally defined as "a person's state of embeddedness in, of undifferentiation within, the relational context" (Karpel, 1976, p. 67). It is thought to represent a prolonged state of intense intimacy, in which members of a couple become so physically and emotionally close that they experience a sense of loss of their own individuality or separateness (Bowen, 1966; Pearlman, 1989).

The term fusion has been used interchangeably with such terms as merger (Burch, 1982; Iguarta, 1998), enmeshment (Pardie \& Herb, 1997; Zacks et al., 1988) and embeddedness (Karpel, 1976). However, there is some debate as to which term is the most appropriate to use. Some advocate use of the term "enmeshment" because it implies a temporary state of closeness, which is deemed as less pathological (Pardie \& Herb, 1997). Others have consistently used the terms "merger" and "fusion" to indicate a permanent state of closeness (Elise, 1986; Iguarta, 1998). Despite evident questioning of the labels, the term "fusion" will be maintained and used in the proposed research. Although this term has typically carried deeply negative connotations for the dynamics of lesbian relationships, it is my contention that it cannot be adequately reclaimed and depathologized if it is not employed in the first place.

Origin of Fusion in Theories of Family Enmeshment

In the family literature, the fusion dynamic has been typically referred to as enmeshment (Minuchin, 1974). Family therapists and researchers were some of the first to label fusion as dysfunctional when it occurred in family and couple relationships. Bowen's (1966) theory of family relations focused on what he called the "undifferentiated 
family ego mass" (p. 355). This refers to a family dynamic in which there is such a lack of sufficient self-differentiation among family members that relationships within the family tend to cycle between phases of extreme closeness, comfortable closeness, and hostile rejection (Bowen, 1966).

Bowen (1966) suggested that fusion occurs in couples when both partners bring their dependency needs into the relationship, thereby repeating those dysfunctional characteristics of their former family relationships. Both partners are said to therefore form a new relationship that pays little attention to individual boundaries, and that results in the merging of the two separate selves into a "common self" (Bowen, 1966, p. 360). Such fusion is considered to have a number of harmful outcomes for couples, such as creating conflict between partners, and projection of difficulties onto children (Bowen, 1966). These outcomes have typically encouraged family therapists to view any kind of fusion as dysfunctional, and therefore something to be fixed.

The discussion of fusion in the family context has also emphasized the role of boundaries among family members and family subsystems. Minuchin (1974) suggested that the family consists of organized subsystems (spouse subsystem, sibling subsystem), defined by boundaries, which lie on a continuum ranging from diffuse to rigid. If one or more family subsystems functions at the diffuse end of the continuum, these family relationships are enmeshed (Minuchin, 1974). However, if family relationships function at the rigid end of the continuum, they are disengaged (Minuchin, 1974). Both enmeshment and disengagement are considered dysfunctional, and healthy relationship functioning is postulated to lie in the middle of the continuum (Minuchin, 1974).

Olson's Circumplex Model (1979) has also influenced greatly the conceptualization of aspects of closeness in family and couple relationships. Olson and his colleagues used 
the dimensions of cohesion and adaptability to derive a model of 16 kinds of marital and family processes (Olson, McCubbin, Barnes, Larsen, Muxen \& Wilson, 1983). According to the Circumplex model, healthy, functional family relationships consist of moderate and balanced levels of cohesion and adaptability (Olson et al., 1983). Similar to Minuchin's (1974) conceptualization, Olson regarded relationships that involved too much cohesion as enmeshed, and those that involved too little cohesion as disengaged (Olson et al., 1983).

These early theories and models of family and relationship functioning are limited in their usefulness for explaining the dynamics of lesbian relationships. They are biased in their implication that the desire for maintaining independence and differentiation in relationships is superior to the desire for closeness and dependence in relationships (Zacks et al., 1988). This bias is reflected in Bowen's (1966) claim that the ability to differentiate the self from others shows "the highest levels of human functioning" (Bowen, 1966, p. 356). Such theories are considered to be androcentric or male-centered in their view of relationship functioning because typically, men are the ones to desire the "superior" value of independence and women are the ones to desire the "inferior" value of closeness. These male-centred theories therefore imply that women's greater need for intimacy and dependence in their relationships is unhealthy. Furthermore, they imply that lesbian relationships are dysfunctional because such relationships involve two women whose relational styles may lead them to desire intense levels of closeness at the expense of individual autonomy.

Fusion in Lesbian Relationships

Fusion has been suggested to be a more frequent problem in lesbian relationships than in heterosexual relationships (Berg-Cross, 1988; Krestan \& Bepko, 1980; Lindenbaum, 
1985; Pearlman, 1989). In their clinical work with lesbian couples, Krestan and Bepko (1980) found that fusion was the underlying theme in many of the problems lesbian couples were reporting. These couples also seemed to experience high levels of anxiety when any need for autonomy was expressed (Krestan \& Bepko, 1980). In an empirical study, Zacks et al. (1988) found that lesbians showed higher levels of cohesion in their relationships than did heterosexual couples. Moreover, almost half of the lesbian relationships (46\%) compared to only $2.9 \%$ of the heterosexual relationships were characterized as enmeshed (Zacks et al., 1988).

Typically, the literature has depicted lesbians as placing such a high value on intimacy, sharing and mutual understanding in their romantic relationships that they downplay differences and conflict (Causby, Lockhart, White \& Green, 1995). Individual partners are said to become so highly attuned to fulfilling each other's needs and desires that their own needs are often compromised (Burch, 1986). Thus, lesbian relationships are considered to suffer from a merging of personal identities and a blurring of individual boundaries.

When such merging or fusion occurs for prolonged periods of time, or becomes a pervasive quality of the relationship, the relationship is said to become dysfunctional (Burch, 1985, 1986). Issues often arise when one woman finds the intense intimacy threatening and wants to create more distance in the relationship (Burch, 1982). This woman might have difficulties with creating distance if her partner perceives the behaviour as a rejection or betrayal (Burch, 1982). A sufficient lack of differentiation between partners may result in other relational problems such as withdrawal from sexual activity, polarization of emotions (Burch, 1986) and low self-esteem (Pearlman, 1989). In addition, fusion has been suggested to lead to more severe dysfunctions such as 
depression, anxiety and violence in lesbian relationships (Bepko \& Johnson, 2000;

Causby et al., 1995; Krestan \& Bepko, 1980).

The behaviours of pathologically fused lesbian couples have been portrayed in many ways. For instance, couples have been observed as trying to spend most of their leisure time together (Causby et al., 1995; Greene et al., 1999), having difficulties in choosing and performing separate activities (Elise, 1986), having the same friends and acquaintances, sharing professional services such as doctors and therapists, as well as sharing material possessions such as clothing, money and cars (Greene et al., 1999). Burch (1986) indicated that dysfunctional fusion might also be identified in the communication patterns of lesbian couples. Such couples are claimed to speak "as if they were one person" (p. 60), with one partner often finishing the other's sentences, interrupting when the other is addressed and assuming that she knows what the other is thinking (Burch, 1986).

However, some of these characterizations of dysfunctional fusion raise questions about the ways in which fusion has been generally defined. For instance, some of the behaviours that Greene et al. (1999) depicted as negative fusion (e.g. sharing money and having the same friends) are portrayed by other researchers as indicative of lesbians' investment in their relationships (Beals, Impett \& Peplau, 2002). Because relationship investment is a positive characteristic, such behaviours should not be confused with negative fusion behaviours. Lesbians cannot be assumed to be dysfunctionally fused when they are simply highly invested in their relationships.

Another concern is that some of these depictions of fusion have arisen only in the context of therapy with lesbian couples (Burch, 1986; Krestan \& Bepko, 1980), and therefore, have not been sufficiently, empirically validated with non-clinical lesbian 
populations. Furthermore, most of these depictions do not differentiate between what could possibly be positive and negative aspects of fusion. Instead, researchers and clinicians have labelled all instances of fusion as negative, based on the belief that any sort of intense closeness or merging of boundaries and identities in romantic relationships is pathological. Although, some researchers have recently attempted to make a distinction between positive and negative patterns of closeness in both heterosexual and same-sex relationships (Werner \& Green, 1999), more research is needed to examine the actual behaviours of lesbian partners that might reflect positive or negative closeness.

A final problem with these behavioural depictions of fusion in lesbian relationships is that they are based on heterosexual models of relationships (Mencher, 1990). The traditional heterosexual conceptualization of a romantic relationship has been one in which the woman is dependent and seeks to connect with the man, whereas the man is independent and attempts to pull away from the woman (Elise, 1986; Krestan \& Bepko, 1980). Thus, there is said to be a division of emotional roles in heterosexual relationships, where the woman offers connectedness and the man offers boundary maintenance (Burch, 1985). This dynamic is considered as promoting a natural emotional separation between opposite sex partners. Thus, according to this heterosexual conceptualization, behaviours such as sharing friends and money, as well as spending a lot of time together are often perceived as negative because they impede the separate functioning of individual partners.

Some have also criticized these notions as male-centered, claiming that they are perpetuated by a patriarchal society that elevates values of separateness and autonomy over values of dependence and relatedness (Burch, 1985). The ideas that separation is the goal of human psychosocial development and that separateness equals maturity, as 
propagated by early developmental and family theorists (Bowen, 1966; Erikson, 1959;

Mahler, 1975), are regarded as biased against women and may not accurately reflect women's patterns of emotional development (Miller, 1991; Surrey, 1991).

\section{Theories for Fusion in Lesbian Relationships}

Several theories have been postulated for the occurrence of fusion in lesbian relationships. Systems theory suggests that it is difficult for lesbian couples to define the boundaries of their relationships in a society that does not respect and validate homosexuality (Krestan \& Bepko, 1980). Lack of societal affirmation is considered to cause a sense of loss of control on the part of the couple, and fusion occurs as a direct attempt to regain control (Greene et al., 1999; Krestan \& Bepko, 1980). Thus, lesbian partners turn to each other for validation and support, and look to their relationship as a source of protection from society's predominantly homophobic and heterosexist attitudes (Burch, 1986; Greene et al., 1999; Krestan \& Bepko, 1980). In this way, lesbian couples place demands on the relationship for meeting all emotional and physical needs (Greene et al., 1999). This tendency results in a closed relationship, in which partners isolate themselves from those around them, and especially from those who are inclined to react negatively to the relationship (Krestan \& Bepko, 1980). Consequently, partners become intimate to the degree that individual boundaries become indistinct, and each partner's autonomy is compromised.

A second theory that has been postulated to explain fusion is that of gender-role socialization, specifically, the ways in which women are socialized to view and behave in their romantic relationships (Krestan \& Bepko, 1978; Peplau, Cochran, Rook \& Padesky, 1978). Traditionally, society has encouraged women to place a higher value on dependence than on autonomy in their relationships, and to put the needs of their partners 
and children above their own (Krestan \& Bepko, 1980). Thus, it is thought that in the context of a lesbian relationship, fusion occurs because the desire for closeness and dependence is intensified, and neither woman is able to maintain her individuality in the relationship (Krestan \& Bepko, 1980).

A third theory that has been used to explain why fusion might occur so frequently in lesbian relationships is that of gender differences in the developmental process of separation-individuation (Chodorow, 1978). According to this theory, because mother and daughter share the similarity of being female, a daughter's process of separation from her mother is never as complete as a son's (Chodorow, 1978). This leads to boundary confusion and a lack of separateness between mother and daughter (Chodorow, 1978). Thus, as girls grow into women, they learn to "experience themselves... as having more permeable ego boundaries... [and] come to define themselves more in relation to others" (Chodorow, 1978, p. 93). According to Chodorow (1978), a woman's pattern of separation-individuation has both its advantages and disadvantages for a lesbian relationship. Whereas it results in a greater ability for lesbian partners to relate intimately to each other, it also makes it difficult for each partner to maintain her autonomy within the relationship, resulting in the tendency for the couple to become fused (Chodorow, 1978).

A final theory for fusion in lesbian relationships has to do with the development and growth of the relationship itself. Pearlman (1989) proposed two stages in the development of the lesbian relationship. The first stage is one in which intense bonding occurs, resulting in the loss of individuality and ego boundaries (Pearlman, 1989). In the second stage of the relationship however, partners begin to re-define their individual boundaries and often feel the need to be more separate from each other (Pearlman, 1989). According 
to these theories, intermittent fusion that occurs in the initial stage of a relationship is natural and beneficial for partners as well as for the relationship (Burch, 1982; Pearlman, 1989). However, fusion becomes dysfunctional when it is prolonged into the second and following stages of the relationship and the couple is unable to achieve differentiation due to denial of differences and avoidance of conflict (Colwell, 1988; Igartua, 1998; Pearlman, 1989).

Although they seem to be able to explain the occurrence of fusion in lesbian relationships, all of the above theories contain problems in their rationale and their implications. One major concern is that each theory by itself simply cannot explain or account for all the factors that might influence a lesbian couple to be fused. For instance, if systems theory is completely accurate in its explanation that fusion occurs in lesbian relationships due to the lack of validation from society for these relationships, then why is it that gay male relationships are not also typically labelled as being fused? In fact, gay male relationships are often stereotyped as being the opposite to lesbian relationships, in terms of intimacy, in that they are often labelled as being too disengaged (Krestan \& Bepko, 1980).

A problem inherent to theories of gender-role socialization and separationindividuation is their implication that women's patterns of psychosocial development are pathological because they create the potential for women to be fused in their relationships, especially in their lesbian relationships. Thus, such theories place undeserved criticism on women for socialization and developmental processes that, even if they do actually occur in the specified ways, are not consciously chosen nor controlled by women. Moreover, they imply criticism of a lesbian sexual identity, by suggesting that 
women's 'developmental problems' are manifested most when they form sexually intimate relationships with each other.

Moreover, such models and theories about patterns of closeness in relationships are based on the assumption that intimacy has to be reached at the expense of autonomy, and that the two cannot exist together. However, it is important to consider that the norms of lesbian relationships may be different from those of heterosexual relationships (Bepko \& Johnson, 2000). Schreurs and Buunk (1996) found that for lesbian couples, intimacy and autonomy were not correlated, and couples were able to achieve intimacy without having their autonomy reduced. Thus, it may be that perhaps lesbian couples can achieve both high levels of intimacy and high levels of autonomy simultaneously.

\section{Re-defining Fusion}

The inherent bias in the manner in which fusion in lesbian couples was characterized and viewed in early psychological literature has led to a renewed interest in re-examining and re-defining notions of fusion. Hence, many efforts have been made to de-pathologize the occurrence of fusion in lesbian relationships by emphasizing the strengths and benefits that fusion might also have for lesbian couples (Burch, 1985; Greene et al., 1999; Green \& Werner, 1996; Mencher \& Slater, 1991; Pardie \& Herb, 1997). Burch (1982, 1985, 1986) suggested that women cycle through phases of fusion with and separation from their partners, and that this cycle is an important process in the development of both the relationship and each partner's self-identity. Other authors have suggested that fusion in lesbian couples represents an adaptive and functional response that serves to protect the couple's identity and boundaries in a typically homophobic and hostile environment (Greene et al., 1999; Mencher \& Slater, 1991). 
Some feminist authors have rallied for the use of female-centered models of psychosocial development for understanding women's relationship needs and behaviours (Jordan, Kaplan, Miller, Stiver \& Surrey, 1991; Mencher, 1990). Female-centered models view women's self-identity as being shaped by and developed within a relational context (Miller, 1991; Surrey, 1991). Thus for women, the goal of psychosocial development might be the ability to relate intimately with others, rather than maintaining autonomy from others. Most importantly, although they may be different, women's capacities for greater relatedness and intimacy should not be regarded as inferior to men's capacities for greater differentiation and individuation (Miller, 1991; Surrey, 1991). Thus, if women's self-identity is viewed as developing within a relational context, fusion might be regarded as a natural occurrence in women's lesbian relationships (Mencher, 1990). It might also be considered a positive form of intimacy, in the context of a lesbian relationship, because fusion may not always imply a loss of individuality, and because diffusion of boundaries may not always be experienced as negative.

As mentioned earlier, some authors have also heavily criticized the tendency in psychological research to base the dynamics of lesbian relationships, particularly patterns of intimacy and fusion, on heterosexual norms and models of relationships (Bepko \& Johnson, 2000; Igartua, 1998). Traditional heterosexual norms mandate that 'healthy' relationships require a constant balance of autonomy and intimacy, which is naturally provided by the male-female dynamic (Burch, 1985). However, when such norms are applied to the dynamics of lesbian relationships, lesbian relationships are regarded as deviant, and fusion is viewed as dysfunctional because fusion naturally digresses from the autonomy-intimacy balance (Igartua, 1998). 
Therapists and clinicians have been widely criticized for and cautioned against promoting heterosexual models as the standard for all relationship types (Biaggio, Coan \& Adams, 2002; Igartua, 1998). In therapy with lesbian couples, therapists have often pathologized positive patterns of intimacy simply because these patterns do not conform to traditional heterosexual norms (Green \& Werner, 1996). Biaggio et al. (2002) have urged therapists to recognize that evidence of higher levels of intimacy and cohesion in lesbian couples may simply be a reflection of high degrees of trust and commitment. Therapists have also been encouraged to familiarize themselves with the unique and specific aspects of lesbian relationships and women's development, as well as to avoid making assumptions about what a lesbian couple's problems might be (Biaggio et al., 2002; Igartua, 1998; Murphy, 1992). It is also important to recognize that some lesbian couples may simply enjoy spending a lot of time together and may be able to resolve issues of sharing activities and time much more easily than heterosexual couples (Finch, 1999). This could be due to as simple an explanation as lesbian partners potentially having more common interests than opposite sex partners. These possibilities remain to be explored in future research.

\section{Empirical Research on Fusion}

In the past, much of the literature on fusion in lesbian relationships has been theoretical and has originated from observations of lesbian couples in therapy (Krestan \& Bepko, 1980). More recently, researchers have begun studying the notion of lesbian couple fusion empirically, in an effort to provide more valid and accurate accounts of how and why fusion occurs. These researchers have made efforts to examine fusion among non-clinical lesbian populations, claiming that past theory on fusion has been biased by focussing mainly on couples in therapy (Hill, 1999). Some studies have also 
been interested in comparing fusion in lesbian couples with fusion in heterosexual couples (Greene et al., 1999; Hornstein, 1996).

What have such empirical studies discovered about fusion in lesbian relationships, and have the findings conformed to past theoretical conceptualizations of fusion? On the one hand, some studies have found that fusion does not occur significantly more frequently and intensely in lesbian relationships than in heterosexual and gay male relationships (Colwell, 1988; Greene et al., 1999; Hornstein, 1996). In fact, when fusion was actually found in lesbian relationships, it was reported to exist at only moderate levels (Causby et al., 1995; Greene et al., 1999) and to be comparable to levels of fusion in heterosexual couples as well (Green et al., 1999).

On the other hand, other studies have found lesbian couples to have much higher levels of cohesion (Zacks et al., 1988), as well as emotional and recreational intimacy than heterosexual couples (Schreurs \& Buunk, 1995). Lesbian couples have also been reported to have less of a fear of intimacy than heterosexual women (Hornstein, 1996). Furthermore, lesbian couples with high degrees of intimacy and cohesion have often reported being just as satisfied with their relationships as heterosexual couples (Eldridge \& Gilbert, 1990; Greene et al., 1999; Kurdek \& Schmitt, 1986; Mencher, 1984; Peplau, Cochran, Rook \& Padesky, 1978; Schreurs \& Buunk, 1995, 1996), and in some cases, have even reported being more satisfied than heterosexual couples (Zacks et al., 1988). Thus, the evidence indicates that, although high levels of intimacy and closeness are generally desired in lesbian relationships, only moderate levels of fusion are actually reported in these relationships. These studies have clearly distinguished between intimacy and fusion, and have placed fusion on its own continuum with moderate levels of fusion 
being healthy and high levels of fusion being labelled as pathological (Causby et al., 1995; Greene et al., 1999).

In order to obtain a better understanding of fusion in lesbian couples, researchers have attempted to examine several variables in relation to fusion. In addition to relationship satisfaction (Finch, 1999; Greene et al., 1999), these variables have included social support (Hill, 1999; Hornstein, 1996; Roper, 1997), outness (Hill, 1999; Roper, 1997), attachment style (McBain, 2000), age (Greene et al., 1999; Hornstein, 1996), length of the relationship (Greene et al., 1999; Hornstein, 1996), intimacy and closeness (Blyth \& Straker, 1996; Greene et al., 1999), conflict and physical violence (Causby et al., 1995), frequency of sexual contact (Blyth \& Straker, 1996; Hornstein, 1996), dependency (Greene et al., 1999), and autonomy (Greene et al., 1999). The variables of particular interest to the current study are age, attachment style, social support, outness, and relationship satisfaction.

Age

The two studies that have specifically examined how age relates to fusion in lesbian relationships have found that older women reported less fusion in their relationships than did younger women (Greene et al., 1999; Hornstein, 1996). Levitz-Jones and Orlofsky (1985) reported that in their sample of predominantly heterosexual, college-aged women, almost $60 \%$ of women "exhibited a high degree of needfulness, ambivalence, and enmeshment in their relationships" (p. 167-168). Thus, it appears that patterns of fusion may be exhibited in the relationships of young, heterosexual women as well. This suggests the possibility that fusion is more closely related to the age and therefore, the psychological maturity of the individual, than to issues of sexual orientation or gender 
socialization. However, so far, no theories about fusion in lesbian relationships have considered and included age as a factor.

Greene et al. (1999) have suggested that, because younger lesbians have not had as much time as older lesbians to develop external support systems that would protect them from a hostile and homophobic society, they might experience more difficulty in coping with negative reactions toward their sexual orientation. Thus, younger lesbians may be more likely than older lesbians to view their relationship as their only source of protection and support, and thereby may be more likely to become fused with their partners. By this explanation, Greene et al. (1999) have suggested that the relationship between age and fusion might provide support for systems theory for fusion.

\section{Attachment Style}

Bowlby (1977) suggested that the attachment system developed in order to preserve the child's proximity to the caregiver when the child was faced with danger or threat. Thus, the attachment system not only ensures the child's survival in a potentially threatening environment, but it also provides the child with a secure base from which he or she can explore and learn about the environment (Ainsworth, Blehar, Waters, \& Wall, 1978). Bowlby (1973) thought that over time, children would internalize their experiences with their primary caregivers to form internal working models of attachment. These working models would be based on children's perceptions of the self and perceptions of others, and would become the standard by which children judged and behaved in their close relationships with others (Bowlby, 1973).

Based on Bowlby's theory of attachment, Mary Ainsworth (1978) derived three main attachment patterns that an infant could have with his or her caregiver: Secure, Anxiousambivalent and Avoidant. Today this three-group conceptualization of attachment is 
widely applied and investigated in much of the research on attachment styles. One of its most important applications and extensions is to the study of adult attachment. Because an underlying principle of attachment theory is that infant attachment relationships provide a model for other relationships throughout the individual's life (Bowlby, 1973, 1977), several researchers have seen it fit to investigate the stability and continuity of attachment patterns, and to apply these patterns to understanding people's behaviours in romantic relationships (Collins \& Read, 1990; Feeney \& Noller, 1990; Hazan \& Shaver, 1987). Such behaviours have become known as adult attachment behaviours.

Hazan and Shaver (1987) were among the first to relate infant attachment styles to adult attachment in romantic relationships. They developed a measure of three adult attachment categories that corresponded to Ainsworth's (1978) attachment patterns. Thus, adults were also classified as secure, anxious-ambivalent, and avoidant in their romantic relationships (Hazan \& Shaver, 1987). Subsequent studies using this measure of adult attachment have shown that persons who are insecurely attached, that is, those with avoidant and anxious-ambivalent attachment styles, tend to have more difficulties in and report being less satisfied with their relationships than those who are securely attached (Brennan \& Shaver, 1995; Collins \& Read, 1990; Feeney \& Noller, 1990; Hazan \& Shaver, 1987).

In 1990, Kim Bartholomew proposed an expansion of Hazan and Shaver's (1987) typology of adult attachment. Her proposed typology was based on Bowlby's (1973) notion that the child's internal representations of relationships or working models were products of models of the self and models of the other. Hence, she developed a fourcategory typology of adult attachment based on the interactions of positive and negative models of self and other (see Appendix A) (Bartholomew, 1990). The four attachment 
classifications consisted of: Secure, Preoccupied, Fearful and Dismissing (Bartholomew, 1990; Bartholomew \& Horowitz, 1991). This new model of adult attachment split Hazan and Shaver's (1987) avoidant classification into two groups of avoidant persons: people who desire intimacy, but are afraid of being rejected and so avoid closeness in their relationships (fearful); and people who claim not to desire close relationships or intimacy at all (dismissing). The secure and preoccupied categories correspond to Hazan and Shaver's (1987) secure and anxious-ambivalent styles respectively.

According to this typology, secure individuals are characterized as having positive models of both self and other. Such persons have a strong sense of self-worth, are generally comfortable with intimacy in their relationships, and are able to maintain autonomy within their relationships (Bartholomew, 1990; Bartholomew \& Horowitz, 1991). A secure attachment has also been related to greater relationship interdependence, trust, and satisfaction (Simpson, 1990).

Preoccupied people are thought to have a negative image of self and a positive image of other. They are usually characterized as overly dependent in their relationships and possessing strong feelings of unworthiness (Bartholomew, 1990). Preoccupied people also tend to be more hypervigilant and become easily jealous in their close relationships than people of other attachment styles (Buunk, 1997; Sharpsteen \& Kirkpatrick, 1997).

Fearful individuals are those who possess a negative image of both self and other. Although they often desire intimate relationships, they avoid such relationships out of a fear of rejection and a mistrust of others (Bartholomew, 1990; Bartholomew \& Horowitz, 1991). Fearful people have been found to score low on self-disclosure, self-confidence and level of romantic involvement (Bartholomew \& Horowitz, 1991). 
Dismissing people have a positive image of self and a negative image of other. They perceive themselves as completely self-reliant and so often downplay the importance of having close relationships (Bartholomew, 1990; Bartholomew \& Horowitz, 1991). When faced with rejection by attachment figures dismissing people maintain their positive selfview by distancing themselves from their partners (Bartholomew, 1990). In this way, the dismissing attachment style has sometimes been described as a defensive style (Cassidy \& Kobak, 1988).

Researchers have successfully related adult attachment to other variables relevant to romantic relationships. These variables have included trust (Simpson, 1990), commitment (Simpson, 1990), intimacy (Greenfield \& Thelen, 1997; Senchak \& Leonard, 1992), interdependence (Simpson, 1990), relationship aggression (Senchak \& Leonard, 1992), and satisfaction (Collins \& Read, 1990; Feeney \& Noller, 1990). However, most of the research examines these dynamics in heterosexual romantic relationships. Generally, research on adult attachment with lesbian and gay male populations is scarce.

Greenfield and Thelen (1997) however, sought to examine the association between adult attachment and fear of intimacy in a gay and lesbian population. They found that lesbians with anxious/ambivalent and avoidant attachment styles had a greater fear of intimacy than did those with a secure attachment (Greenfield \& Thelen, 1997). They also found that gay men with avoidant attachments had a greater fear of intimacy than did those with secure or anxious-ambivalent attachments (Greenfield \& Thelen, 1997). These findings provide validation for the adult attachment classifications regarding how intimacy in relationships is perceived.

Studying the association between adult attachment and fear of intimacy in lesbian couples might conceivably provoke a study of how attachment relates to fusion in these 
couples. This is because, although fusion and intimacy have been found not to be the same constructs (Blyth \& Straker, 1996), they would possibly have many behavioural characteristics in common. Thus far, only one unpublished study has examined the association between adult attachment and fusion in lesbian relationships. McBain (2000) found that women with anxious-ambivalent attachment styles indicated high levels of fusion in their relationships. Levitz-Jones and Orlofsky (1985) also investigated the relationship between attachment and patterns of intimacy and fusion, although they used a population of heterosexual women. This study placed fusion at the extreme end of an intimacy continuum. The authors found that women with more severe, anxious attachments reported either greater enmeshment (fusion) or lower intimacy in their relationships than women with milder anxious attachments (Levitz-Jones \& Orlofsky, 1985).

As McBain (2000) suggests, examining adult attachment as it relates to fusion contributes to our further understanding of how and why fusion might occur in lesbian couples, and indeed in heterosexual couples as well. This understanding would be especially helpful in clinical settings, such as therapy with lesbian couples, who are experiencing problems directly related to fusion (McBain, 2000). Moreover, the study of the association between attachment and fusion provides a discussion of how individual differences and psychological characteristics might contribute to fusion in lesbian relationships. Thus far, theories explaining the occurrence of fusion in lesbian relationships have focussed mainly on social factors, specifically the ways in which women are socialized and the impact of society's homophobic reactions. Although it is vital to acknowledge the influence of social forces and societal reactions, it is important 
to examine how psychological and developmental characteristics of the individual might also have an impact on fusion in lesbian relationships.

\section{Social Support}

Social support has been defined as "perceived or actual instrumental and/or expressive provisions supplied by the community, social networks, and confiding partners" (Lin, 1986, p. 18). Social support can be received from different sources such as friends, family, and significant others (Zimet, Dahlem, Zimet, \& Farley, 1988). In addition, social support has been thought to serve different functions such as providing reassurance of worth, guidance, opportunities for social integration and caretaking, a sense of security, and material assistance (Weiss, 1974).

Social support has long been regarded as a coping resource for individuals, and research has shown that as long as it is perceived to be available and adequate, it can lead to greater individual physical and psychological well-being (Cohen \& Wills, 1985). The amount of perceived social support appears to be generally similar for both lesbian and heterosexual women (Wayment \& Peplau, 1995). However, small differences have been found between lesbian and heterosexual women in their reported sources of social support.

Kurdek (1988) found that lesbians identified friends and romantic partners as being more supportive than family members and co-workers, whereas, heterosexual persons reported partners and family members to be more supportive than friends. Hornstein (1996) also showed that lesbians sought more support from friends, whereas heterosexual women sought more support from family members. These findings are conceivable given that family reactions to homosexuality and coming out tend to be more strongly negative than the reactions of friends. However, Olson (1988) found that support from friends and 
family members were most predictive of lesbians' psychological well-being. Thus, although women in lesbian relationships report receiving less support from family members than from friends and partners, they still seem to value the importance of receiving support from family members.

Lesbian and heterosexual women also seem to differ in the kind of social support they receive from their support networks. For example, Wayment and Peplau (1995) found that lesbian women's psychological well-being was most significantly impacted by support defined as reassurance of worth, whereas heterosexual women's well-being was most impacted by guidance support. Reassurance of worth is support that provides a sense of being competent and appreciated for one's abilities and social roles (Weiss, 1974). Guidance support is support from trustworthy people, who offer advice and counsel (Weiss, 1974).

Wayment and Peplau (1995) suggest that reassurance of worth may be more valuable to lesbians because it makes them feel accepted and admired for who they truly are, especially in a world that generally does not validate homosexuality. Despite this, Roper (1997) found that for her sample of lesbians, being out to friends was not necessary to feeling supported by them (Roper, 1997). Furthermore, she found low correlations between overall social support and support of lesbian identity, implying that perhaps these two types of social support serve different functions. Roper (1997) speculates that, for lesbians, social support may have greater value as an assurance of one's worth as a woman, than as a validation of one's sexual orientation. These differences are intriguing, because they question the value of being out to social support networks for lesbians' psychological well-being. 
Because systems theory has generally focussed on the impact of the social environment on lesbian couples' tendencies toward fusion (Krestan \& Bepko, 1980), social support has been examined as an important factor in relation to fusion in lesbian relationships. Generally, findings support the notion that less support and validation from one's social environment is associated with increased fusion in romantic relationships (Hornstein, 1996; Roper, 1997). These findings are suggested to indicate that as women perceive having greater support and affirmation from friends, family and co-workers, they put less pressure on their romantic relationships for providing for all of their emotional needs (Hornstein, 1996; Roper, 1997). However, given that these findings are all correlational, Roper (1997) has suggested that the relationship between social support and fusion may work in the opposite direction. Thus, she speculates that women who are less fused with their partners may have more time to invest in and spend with their friends, family and co-workers, and hence, may perceive receiving greater social support from these networks (Roper, 1997).

Despite these findings for negative associations between social support and fusion, some researchers have found that even when lesbian women have available, adequate and positive social support networks, they still have fused relationships (Krieger, 1983). Furthermore, some studies have found that less perceived social support do not result in fusion for lesbian couples (Colwell, 1988). Given the numerous inconsistencies in the literature, it is important to continue examining the association that social support might have with fusion in lesbian relationships.

\section{Outness}

Every day, gay, lesbian and bisexual individuals are forced to deal with the consequences of coming and being out in a society that is, for the most part, intolerant of 
homosexuality. Whereas some choose to remain "closeted," that is, to not disclose their sexual orientation to others, others choose to completely "come out of the closet." Additionally, some people are more selective in to whom they disclose their sexual orientation. Although, the state of being out has been labelled in a variety of ways, for the purposes of the proposed study, the term "outness" will be used.

Outness has been associated with both benefits and costs for gay and lesbian individuals (Beals \& Peplau, 2001). Some of the identified risks and costs include rejection by family of origin, loss of custody of one's children, and being a victim of gay and lesbian bashing (Cohen \& Savin-Williams, 1996). For this reason, many gay men, lesbians and bisexual women choose to either remain fully closeted, or to be out as much as they can be without risking harm to themselves. However, several benefits have also been shown to occur as a result of coming out to friends, family and co-workers. These include higher self-esteem, less anxiety (Jordan \& Deluty, 1998), overall improved psychological health (Kahn, 1991), and physical health (Cole, Kemeny, Taylor, \& Visscher, 1996).

Outness has also often been examined in the context of romantic relationships. Its associations with relationship satisfaction and relationship quality have been explored in many studies with lesbian couples (Beals \& Peplau, 2001; Caron \& Ulin, 1997; Eldridge \& Gilbert, 1990; Green et al., 1996; Murphy, 1989). These studies have sometimes produced inconsistent findings regarding whether outness is at all related to relationship quality and satisfaction. Whereas some studies so far have shown that outness is not related to either relationship satisfaction (Eldridge \& Gilbert, 1990; Green et al., 1996) or relationship quality (Beals \& Peplau, 2001), other studies have found support for a positive association between the two (Caron \& Ulin, 1997; Murphy, 1989). 
The concept of outness is very closely related to the concept of social support, because the degree to which one is out to one's social networks will determine the amount of support one can receive from these networks for one's sexual orientation and romantic relationships (Caron \& Ulin, 1997; Roper, 1997). For example, Jordan and Deluty (1998) found that higher levels of outness were related to greater perceived social support. In this manner, outness can also be related to fusion in lesbian couples. Similar to the argument for the impact of social support, authors have postulated that lesbians who have to remain closeted about their identity and relationships will be more fused in their relationships (Krestan \& Bepko, 1980). Indeed, this is conceivable, because lesbians who are not out to their friends, family or co-workers cannot turn to these people for support, advice or comfort regarding their romantic relationships. Given that their partners are the only ones to whom they are out, these women may end up being too dependent on the relationship for providing all emotional support. This may be a partial explanation for Hornstein's (1996) finding that during times of conflict with their partner, lesbian women turned more to the partner for support than did heterosexual women.

Very few studies have actually related outness to fusion in lesbian relationships however. Through interviews with eight lesbian couples, Hill (1999) found that even when some lesbian couples were faced with rejection by family members for their sexual orientation they were able to turn to their friends for support. Thus, they placed less pressure on the relationship for providing complete emotional support in such a distressing situation. Consequently, Hill (1999) found that her sample of lesbian couples was not generally characterized by fusion. In addition, Roper (1997) found that outness was not, at all, related to fusion in lesbian couples nor was it related to higher levels of healthy intimacy. In summary, it seems that outness in general may not lead to or affect 
fusion in lesbian relationships. However, given the lack of research into this association, more consistent findings may be needed before firm conclusions can be drawn.

\section{Fusion as Intrusiveness and Closeness-Caregiving}

Efforts to de-pathologize fusion have led some researchers to revise the ways in which the concept of fusion is operationalized and defined. Green and Werner (1996) claimed that both Minuchin's $(1974,1978)$ and Olson's (1993) uses of the term enmeshment to signify forms of closeness in family relationships confused two conceptually different and contradictory notions. Specifically, they cited instances where Minuchin (1978) defined enmeshment as both a lack of self-other differentiation and a form of greater closeness and caregiving in relationships (Green \& Werner, 1996). Furthermore, they criticized Olson's (1993) characterization of enmeshment as high levels of closeness and, in reference to newlywed couples, as "being in love and enjoying spending maximum time together" (Olson, 1993, p. 117-118).

Green and Werner (1996) suggested that these previous definitions of enmeshment have blended both positive and negative types closeness, and have resulted in the mislabelling of positive closeness as a negative occurrence. They suggest that negative types of closeness would be best termed as intrusiveness, and positive types as closenesscaregiving, and that although these two notions may be interrelated, they should be assessed as separate aspects of relationship functioning. Consequently, Green and Werner (1996) defined intrusiveness as behaviours that reflect a lack of adequate self and other differentiation, such as extreme anxiety upon separation from a loved one, jealousy, and possessiveness (Green \& Werner, 1996). Moreover, they defined closeness-caregiving as behaviours that reflect warmth, physical intimacy, and spending quality time together (Green \& Werner, 1996). 
The authors subsequently developed a measure of family functioning called the California Inventory for Family Assessment (CIFA; Werner \& Green, 1999), which measures the dimensions of intrusiveness and closeness-caregiving separately, and which is being increasingly used in research with lesbian couples (Finch, 1999; Roper, 1997). In addition to Green and Werner (1996), Roper (1997) and Finch (1999) have acknowledged that in the past, the issue of fusion in lesbian relationships has been characterized as generally negative, and that researchers and clinicians have not typically paid attention to potential positive aspects of closeness. However, none of these authors explicitly suggest that the concept of fusion be characterized by two separate constructs, at the same time as maintaining the label of fusion. They merely use the terms intrusiveness and closenesscaregiving to denote two separate lesbian relationship dynamics.

Some authors have suggested not using the terms fusion or merger at all to signify the intimacy dynamics of lesbian relationships (Pardie \& Herb, 1997) because the term itself is riddled with negative connotations. However, I believe in the importance of maintaining the terms that are typically used in the literature, and attempting to reclaim their meanings through clarification of definitions and operationalizations. Hence, I proposed a theoretical re-definition of the term fusion that maintains the label, but defines it more specifically as encompassing separate intrusiveness (negative fusion) and closeness-caregiving (positive fusion) behaviours. Moreover, I suggested that if the term fusion is used in research with lesbian couples, researchers should specify whether they mean positive or negative fusion. This would perhaps help to re-define current notions of fusion by ensuring that positive aspects of closeness are not confused with negative aspects of closeness, and that couples who are positively fused are not regarded by clinicians as dysfunctional and in need of help (Finch, 1999; Roper, 1997). 


\section{Measurement Issues}

Using Werner and Green's (1999) measure of intrusiveness and closeness-caregiving to operationalize negative and positive fusion also improves on previous measures of fusion in lesbian relationships. For instance, Causby et al.'s (1995) and Greene et al.'s (1999) measure of fusion was clearly developed under the assumption that fusion was solely negative. The 9-item measure includes items that could be questioned in the extent to which they really indicate any kind of fusion at all, but especially negative fusion. For example, as already mentioned, some of the items ask about behaviours such as sharing money and friends (Greene et al., 1999), which are labelled as negative fusion in this context, but referred to as ordinary relationship investment behaviours in other contexts (Beals et al., 2002).

Other measures of fusion include Colwell's (1988) Merger/Disengagement Scale and the Personal Authority in the Family System Questionnaire (McBain, 2000). Although these measures demonstrate good reliability, they also do not make clear distinctions between what might be positive and negative aspects of fusion. Thus, continued use of Werner and Green's (1999) measure will aid the re-definition of fusion, such that healthy and unhealthy aspects of lesbian relationships are not confused.

\section{Research Questions}

In summary, this study proposed a modification of the way fusion has been typically conceptualized in the psychological literature. I defined fusion as consisting of two separate dimensions: intrusiveness and closeness-caregiving. These dimensions have been postulated to represent, respectively, negative and positive patterns of closeness in intimate and family relationships (Green \& Werner, 1996). This study investigated how particular developmental and social factors might relate to patterns of intrusiveness and 
closeness-caregiving demonstrated by women in lesbian relationships. Age and adult attachment style were examined as developmental variables, and perceived social support and outness were examined as social variables.

Although adult attachment has been previously explored in relation to fusion in lesbian couples (McBain, 2000), as well as in relation to dimensions of intrusiveness and closeness-caregiving in heterosexual couples (Canon, 1999), this study provided an extension to this area of research because it examined specifically, how Bartholomew's (1990) typology of adult attachment was related to patterns of intrusiveness and closeness-caregiving in lesbian relationships. The variables of age, social support and outness have also been previously studied in relation to fusion in lesbian relationships. However, the research has been sparse and sometimes inconsistent, and so further replication and extension of research was considered important. Finally, this study aimed to replicate past findings on the relationship between relationship satisfaction and closeness-caregiving among lesbian couples (Finch, 1999; Roper, 1997).

\section{Hypotheses}

\section{Predicting Intrusiveness}

I expected that age, attachment, social support, and outness would be significant predictors of intrusiveness. Regarding age, I predicted that women who were older would show less intrusiveness toward their partners. This hypothesis was based on Greene et al.'s (1999) and Hornstein's (1996) findings that older women reported less fusion in their relationships.

Regarding attachment, because a preoccupied attachment is associated with being overly involved and dependent in romantic relationships (Bartholomew, 1990), it was anticipated that women with a preoccupied attachment would show greater intrusiveness 
in their relationships than women with other attachments. This hypothesis was grounded in Green and Werner's (1996) speculation that an anxious-ambivalent attachment style might be associated with greater intrusiveness, and McBain's (2000) finding that women with anxious-ambivalent attachments reported higher fusion in their relationships. Although, McBain (2000) did not define fusion as intrusiveness specifically, her operationalization of fusion as negative was similar to Green and Werner's (1996) intrusiveness concept. Moreover, the anxious-ambivalent attachment type has been shown to be conceptually similar to Bartholomew's preoccupied type (Bartholomew \& Shaver, 1998).

Regarding social support, I hypothesized that women with greater support from friends and family would show lesser intrusiveness in their relationships. The rationale for this hypothesis stemmed from theories suggesting that fusion results from a lack of validation and support from social networks outside of the relationship (Krestan \& Bepko, 1980). This hypothesis was also based on past studies showing that lesser perceived social support was associated with greater merger in lesbian relationships (Hornstein, 1996).

Regarding outness, it was anticipated that women who were more out to social networks would show lesser intrusiveness in their relationships. This finding was expected despite previous suggestions that outness was not related to intrusiveness (Roper, 1997). This hypothesis was based on the rationale that outness might be related to social support, such that women who perceive greater social support from friends and family might also be more out to these social networks (Jordan \& Deluty, 1998). However, because of the lack of empirical support in the literature for the association between outness and intrusiveness this hypothesis was exploratory. 


\section{Predicting Closeness-Caregiving}

I hypothesized that attachment style and social support would be significant predictors of closeness-caregiving. Regarding attachment, I expected that women with secure and preoccupied attachment styles would show greater closeness-caregiving in their relationships than women with other attachment styles. The hypothesis for secure attachment was grounded Green and Werner's (1996) speculation that high levels of closeness-caregiving could be associated with a secure attachment, as well as research findings that secure persons are able to achieve and be comfortable with intimacy in their relationships (Bartholomew, 1990). The hypothesis for preoccupied attachment was exploratory, and was based on the notion that because preoccupied persons place such a high value on having relationships (Bartholomew \& Horowitz, 1991) they might desire and show high levels of closeness with their partners, in addition to perhaps showing high levels of intrusiveness.

Additionally, I hypothesized that because women with dismissing and fearful attachments tend to avoid intimacy with partners these women would demonstrate lower levels of closeness-caregiving in their relationships than women of other attachment styles. This expectation was also based on Green and Werner's (1996) speculation that lower levels of closeness-caregiving might be associated with an avoidant attachment.

Regarding social support, I predicted that women who perceived greater support from friends and family would show greater closeness-caregiving in their relationships. The rationale for this hypothesis stemmed from Roper's (1997) findings that support from friends was related to closeness-caregiving. However, because Roper's (1997) findings were only of marginal significance and because Roper examined closeness-caregiving 
received from partners, instead of closeness-caregiving given to partners, my hypothesis for this relationship was exploratory.

\section{Predicting Relationship Satisfaction}

I hypothesized that closeness-caregiving would significantly predict relationship satisfaction. Thus, women who showed greater closeness-caregiving in their relationships were expected to report greater satisfaction with those relationships. This hypothesis was based on past research, which has found that higher levels of cohesion are associated with greater satisfaction in lesbian relationships (Zacks et al., 1988). Moreover, it was reasonable to expect that because closeness caregiving results in positive outcomes for people in relationships, it would result in psychological well-being and happiness for the woman who demonstrated it. 


\section{CHAPTER II}

\section{Method}

\section{Participants}

Participants were 77 women between the ages of 18 and 62 years $(M=36.9, S D=$ 10.85). At the time of participation, all women had been involved in a romantic relationship with another woman for at least 3 months $(M=73.14$ months, $S D=64.55)$. The majority of women in the sample were lesbian, Caucasian, non-religious, highly educated, and employed with a middle income level (details in Table 1). Thirteen percent of the sample consisted of students. Of these students $40 \%$ had additional jobs. Approximately $60 \%$ of the sample reported living in the Ontario cities of Toronto $(33.8 \%)$, Kingston $(10.4 \%)$, Windsor $(9 \%)$, and Ottawa $(6.5 \%)$, whereas $6.5 \%$ lived in New Brunswick, and $1 \%$ lived in Alberta. The rest of the women reported living in towns and cities throughout Ontario. Eighty percent of women lived with their partners, and of these women, $13 \%$ also lived with their children. Twenty-nine percent of women had children, and of these women, $17 \%$ had children who were biological, $4 \%$ had children who were adopted, and $5 \%$ had children who were step-children. The response rate for this study was $40.3 \%$ (with 191 surveys distributed and 77 returned).

Table 1 also provides some demographic information that was collected about participants' partners. Partners were between the ages of 23 and 61 years $(M=36.81$, SD =9.36). Similar to participants, the majority of partners were lesbian, Caucasian, nonreligious, highly educated, and employed with a middle income level (details in Table 1). 
Table 1

Summary of Demographic Characteristics of Participants and their Partners

\begin{tabular}{|c|c|c|c|c|}
\hline \multirow[b]{2}{*}{ Characteristic } & \multicolumn{2}{|c|}{ Participant } & \multicolumn{2}{|c|}{ Partner } \\
\hline & $\mathrm{n}$ & $\%$ & $\mathrm{n}$ & $\%$ \\
\hline \multicolumn{5}{|l|}{ Sexual Orientation } \\
\hline Lesbian/Gay/Dyke & 63 & 81.8 & 70 & 90.9 \\
\hline Bisexual & 6 & 7.8 & 4 & 5.2 \\
\hline Queer & 6 & 7.8 & 1 & 1.3 \\
\hline Undecided & 0 & 0 & 1 & 1.3 \\
\hline No Response & 2 & 2.6 & 1 & 1.3 \\
\hline \multicolumn{5}{|l|}{ Ethnicity } \\
\hline Caucasian & 65 & 84.4 & 62 & 80.5 \\
\hline East Asian & 4 & 5.2 & 2 & 2.6 \\
\hline East Indian/South Asian & 2 & 2.6 & 4 & 5.2 \\
\hline West Indian & 1 & 1.3 & 2 & 2.6 \\
\hline Metis/Aboriginal & 1 & 1.3 & 1 & 1.3 \\
\hline Arabic/Middle Eastern & 1 & 1.3 & 0 & 0 \\
\hline Latin/Portuguese & 0 & 0 & 2 & 2.6 \\
\hline African/Black & 0 & 0 & 0 & 0 \\
\hline Mixed & 3 & 3.9 & 3 & 3.9 \\
\hline No Response & 0 & 0 & 1 & 1.3 \\
\hline
\end{tabular}


Table 1. (Continued)

\begin{tabular}{|c|c|c|c|c|}
\hline \multirow[b]{2}{*}{ Characteristic } & \multicolumn{2}{|c|}{ Participant } & \multicolumn{2}{|c|}{ Partner } \\
\hline & $\mathrm{n}$ & $\%$ & $\mathrm{n}$ & $\%$ \\
\hline \multicolumn{5}{|c|}{ Religious/Spiritual Identification } \\
\hline None & 52 & 67.6 & 48 & 62.4 \\
\hline Catholic/Other Christian & 11 & 14.3 & 16 & 20.8 \\
\hline Jewish & 5 & 6.5 & 4 & 5.2 \\
\hline Muslim & 1 & 1.3 & 2 & 2.6 \\
\hline Hindu & 1 & 1.3 & 1 & 1.3 \\
\hline Buddhist & 1 & 1.3 & 3 & 3.9 \\
\hline Other & 6 & 7.8 & 3 & 3.9 \\
\hline \multicolumn{5}{|l|}{ Level of Education } \\
\hline High School & 10 & 13.0 & 8 & 10.4 \\
\hline College & 10 & 13.0 & 13 & 16.9 \\
\hline Bachelor's & 21 & 27.3 & 21 & 27.3 \\
\hline Master's & 17 & 22.1 & 12 & 15.6 \\
\hline Ph.D. & 10 & 13.0 & 7 & 9.1 \\
\hline M.D. & 1 & 1.3 & 1 & 1.3 \\
\hline Some university & 7 & 9.1 & 10 & 13.0 \\
\hline Some graduate school & 1 & 1.3 & 1 & 1.3 \\
\hline Other & 0 & 0 & 2 & 2.6 \\
\hline No Response & 0 & 0 & 2 & 2.6 \\
\hline
\end{tabular}


Table 1. (Continued)

Participant

Partner

Characteristic

n

$\%$

n

$\%$

Employment Status

Employed

Unemployed

Retired

Students only

No Response

Annual Income Level

\begin{tabular}{lcccc} 
Less than 10,000 & 7 & 9.1 & 7 & 9.1 \\
$10,000-19,000$ & 12 & 15.6 & 5 & 6.5 \\
$20,000-29,000$ & 11 & 14.3 & 12 & 15.6 \\
$30,000-39,000$ & 11 & 14.3 & 8 & 10.4 \\
$40,000-49,000$ & 8 & 10.4 & 11 & 14.3 \\
$50,000-59,000$ & 10 & 13.0 & 11 & 14.3 \\
$60,000-69,000$ & 8 & 10.4 & 4 & 5.2 \\
$70,000-79,000$ & 2 & 2.6 & 4 & 5.2 \\
$80,000-89,000$ & 2 & 2.6 & 6 & 7.8 \\
$90,000-99,000$ & 4 & 5.2 & 0 & 0 \\
100,000 and over & 1 & 1.3 & 2 & 2.6 \\
No Response & 1 & 1.3 & 7 & 9.1 \\
\hline
\end{tabular}




\section{Procedure}

Women were recruited through a variety of methods such as snowballing, flyer advertisements (see Appendix B), and emails to lesbian and bisexual women's list-serves (see Appendix C). Snowballing methods consisted of requesting participants to pass questionnaire packages onto other women, whom they knew to be in lesbian relationships. The acquaintances of the researcher and the researcher's supervisor, who were not familiar with the hypotheses and purpose of the study, were also requested to participate, or to recruit others to participate.

Flyers were posted in both gay and lesbian-identified, and non-specifically gay and lesbian-identified establishments such as community centres, restaurants, specialty stores, and university campuses. This was done in order to recruit from both the disclosed and hidden lesbian and bisexual women populations, the latter of whom, may not attend gay and lesbian-identified establishments. Emails were sent to lesbian and bisexual women's list-serves, with a special effort to recruit from as many kinds of populations as possible. Hence, email lists that served a range of different organizations and groups were solicited. These included list-serves for student and community support groups, as well as email lists serving groups of a more social nature for lesbian and bisexual women. Emails were also sent to gay and lesbian groups, specifically for people of ethnic and religious minority backgrounds.

Questionnaire packages were distributed in different ways depending on recruitment method. Some participants received packages in the mail, others were handed packages directly by the researcher, and yet others were given packages by other participants. Each participant was given two separate packages in one large envelope. Participants were requested to complete and return one package, and to pass the second package onto 
another woman whom they knew qualified for the study. Each separate package consisted of six questionnaires, a cover letter (see Appendix D), an information sheet (see Appendix E), a post card for requesting feedback, an envelope with pre-paid postage for returning the package, a list of community resources (see Appendix F), and a pen as an incentive for participation.

The cover letter and information sheet stated specific instructions for completing the questionnaire package and returning it by mail to the researcher. The list of support resources contained descriptions of and contact information for community groups and centres for lesbian and bisexual women, such as bisexual and lesbian-friendly distress centres, support groups, and mental health services for women in distress. Participants were asked to read the information sheet and to complete the questionnaires in a quiet, private place. They were assured of the confidentiality of their responses, and were given the right to not complete or return the questionnaires should they have decided to do so. The questionnaires took about 30- 40 minutes to complete.

Participants were instructed to return the questionnaire packages either by mail or directly to the researcher. The postcard included in the package asked participants to indicate their mailing addresses, and whether or not they would have liked feedback upon completion of the study. This postcard was mailed back to the researcher separately from the questionnaire packages. Participants who requested feedback by mail will be mailed a feedback sheet explaining the general purpose and findings of the study by the fall of 2005.

Measures

All participants completed measures assessing intrusiveness and closeness-caregiving, adult attachment style, perceived social support, outness, and relationship satisfaction. 
They were also asked to provide some demographic information. The order in which measures were presented was randomized.

California Inventory for Family Assessment (CIFA; Werner \& Green, 1999). The CIFA is a 182-item questionnaire that assesses intrusiveness and closeness-caregiving as well as other family and relationship dimensions (see Appendix G). The "given" version of the CIFA, adapted for use with lesbian couples, was administered. This is a self-report of the respondent's behaviour toward her partner. Four scales assessed intrusiveness behaviours: separation anxiety, possessiveness/jealousy, emotional interreactivity, and projective mystification (mind-reading). A sample item from the intrusiveness scale reads "It makes me nervous to go out and to do things without her." Five scales assessed closeness-caregiving behaviours: warmth, time together, nurturance, physical intimacy, and consistency. A sample item from the closeness-caregiving scale is "I put a high priority on spending time with her." Each subscale consists of 14 items rated on a 4-point scale, ranging from 1 (very false) to 4 (very true). Higher scores indicate greater closeness-caregiving and intrusiveness.

Internal consistencies for 3 of the intrusiveness scales were good, ranging from .79 to .84. Although, the projective mystification scale produced a reliability that was somewhat lower than the others $(\alpha=.65)$, it was still acceptable and consistent with past reliability estimates found for this scale (Roper, 1997; Werner, Green, Greenberg, Browne \& McKenna, 2001). Internal consistency estimates for the 5 closeness-caregiving scales were high, ranging from .81 to .91 . In general, reliability estimates in this study were consistent with those found by Werner et al. (2001), who used the first edition of the CIFA (containing a true-false response format) with heterosexual married couples. 
However, reliability estimates were somewhat higher than those found by Roper (1997), who used the same 4-point Likert scale version.

The authors of the CIFA computed scores for the 9 subscales that were examined in the main analyses ${ }^{1}$. Following the authors' instructions on computing standardized scores for the closeness-caregiving and intrusiveness scales, the researcher converted subscale scores to $\mathrm{Z}$ scores, and averaged them to produce an intrusiveness $\mathrm{Z}$ score and a closeness-caregiving $\mathrm{Z}$ score. The CIFA also contains 4 scales measuring additional family dimensions such as openness to communication, conflict management, anger, and authority/dominance. Although these scales were administered to participants in order to maintain the integrity of the measure, they were not examined in the main analyses of this study.

Experiences in Close Relationships Inventory (ECR; Brennan et al., 1998). The ECR was used to assess adult attachment style (see Appendix H). This 36-item measure asks people about their feelings and behaviours in romantic relationships. Items on the ECR are scored on a 7-point Likert scale, ranging from 1 (disagree strongly) to 7 (agree strongly). Sample items from the anxiety dimension include: "I need a lot of reassurance that I am loved by my partner" and "I worry about being abandoned." Sample items from the avoidance dimension include: "I try to avoid getting too close to my partner" and "I don't feel comfortable opening up to romantic partners." Higher scores indicate a greater degree of the particular attachment type.

\footnotetext{
${ }^{1}$ Scores computed for this 4-point scale, second research edition of the CIFA were converted to a $0-14$ point scale, in order to be consistent with the first research edition. Subscale scores were computed by the authors according to the following formula: Scale score $=($ sum of responses -14$)$ divided by 3 .
} 
The ECR was constructed on the higher order attachment dimensions of anxiety and avoidance. Internal consistency estimates were high for these dimensions of anxiety $(\alpha=$ $.90)$ and avoidance $(\alpha=.92)$, and were consistent with previous reliability estimates reported by the authors (.91 for anxiety, and .94 for avoidance; Brennan et al., 1998). Based on the two dimensions of anxiety and avoidance, the ECR classifies people into one of four attachment types: secure, preoccupied, fearful, and dismissing. Scoring involved computing mean scores for the anxiety and avoidance sub-scales and substituting these mean scores into particular formulas provided by the authors (see Brennan et al., 1998). This computation generated classification scores for the four attachment groups.

Although the ECR's classification of attachment styles is based on Bartholomew's adult attachment typology, it is not the same measure as the one developed by Bartholomew and colleagues (see Bartholomew \& Horowitz, 1991). Items in the ECR were adapted from Hazan and Shaver's (1987) attachment measure, as well as other previous measures of adult attachment (e.g. Brennan \& Shaver, 1995; Collins \& Read, 1990; Griffin \& Bartholomew, 1994). The ECR was chosen over other adult attachment measures to be used in the current study, because Brennan et al. (1998) have claimed that it may be a more precise measure of adult attachment than previous scales.

Multidimensional Scale of Perceived Social Support (MSPSS; Zimet, Dahlem, Zimet \& Farley, 1988). Perceived social support was assessed with the MSPSS (see Appendix I). This 12-item measure consists of three subscales, which assess an individual's perceptions of social support received from three sources: family, friends and significant other. Although it was administered, the significant other social support scale was not used in the main analyses, because the purpose of this study was to examine social 
support received from sources external to the romantic relationship. Each subscale contains 4 items, which are rated on a 7-point Likert scale, ranging from very strongly disagree (1) to very strongly agree (7). Higher scores indicate greater perceived social support. A sample item from the family subscale is "I get the emotional help and support I need from my family;" and a sample item from the friends subscale is "I can count on my friends when things go wrong."

Reliability estimates were high for the entire measure $(\alpha=.91)$, as well as for the friends $(\alpha=.95)$ and family $(\alpha=.94)$ subscales. These reliabilities were slightly higher than what has been reported in past studies (Zimet et al., 1988), including those, which also sampled women in lesbian relationships (Roper, 1997). Scoring of the MSPSS involved summing item ratings to produce a score for each subscale. The family and friends subscale scores were then summed to produce a total social support score, which was used in the main analyses.

Network-sector Closeting Measure (Caron \& Ulin, 1997). A network-sector "closeting" measure by was employed as a measure of outness (see Appendix J). This measure assesses outness to four different sectors of the respondent's social networks: immediate family, extended family, friends and work associates (Caron \& Ulin, 1997). For administration, the friends network sector was further divided into straight/heterosexual and lesbian/gay/bi friends. Hence, the final questionnaire consisted of four items assessing respondents' level of outness to the five different network sectors. A sample item from the questionnaire is "The people in (group from below) know that I am a lesbian." Items are scored on a 9-point Likert scale, ranging from 1 (strongly agree) to 9 (strongly disagree). Lower scores indicate greater outness. 
Reliability analyses revealed good internal consistency estimates for the immediate and extended family networks ( $\alpha=.82$ and $\alpha=.88$ respectively), the straight friends $(\alpha=$ .73) and co-worker $(\alpha=.84)$ networks, as well as the entire outness measure $(\alpha=.90)$. However, reliability of the outness to lesbian/gay/bi friends network was very low $(\alpha=$ .22). This was most likely due to lack of variability in the sample on this factor, because everyone reported being very out to their lesbian/gay/bi friends (means ranged from 8.22 to 8.90 on a 9 -point scale for the 4 items pertaining to this network). Caron and Ulin (1997) found comparable reliability estimates for their 4 network scales (ranging from $\alpha=$ .78 to $\alpha=.84)$.

Scores for the four items were summed to provide a total score for each of the 5 network sectors. Because of its low reliability, the lesbian/gay/bi friends network factor was excluded from the computation of the total outness score used in the main analyses. The co-workers scale was also excluded from the total outness score, in order to maximize the sample size. Some participants did not answer the outness to co-workers items due to being unemployed or retired at the time of participation. However, because the outness to co-workers scale correlated significantly with the other outness scales that were used (see Table 2) as well as with the total outness score, excluding it from the calculation of the total outness score caused no substantial loss of information. Thus, the total outness score was computed by adding the scores for the immediate family, extended family, and straight friends networks.

Relationship Assessment Scale (RAS; Hendrick, 1988). Relationship satisfaction was measured with the RAS (see Appendix K). This is a 7-item measure, each item of which is rated on 5-point Likert scale. Sample items include "In general, how satisfied are you with your relationship," and "To what extent has your relationship met your original 
Table 2

Intercorrelations among Subscales of the Network-sector Closeting Measure

\begin{tabular}{lllllll}
\hline \multicolumn{1}{c}{ Scale } & 1 & 2 & 3 & 4 & 5 & 6 \\
\hline 1. Immediate Family & -- & & & & \\
2. Extended Family & $.77^{* *}$ & -- & & & \\
3. Straight Friends & $.47^{* *}$ & $.45^{* *}$ & -- & & \\
4. Lesbian/gay/bi Friends & .07 & .04 & .22 & -- & & \\
5. Co-workers & $.40^{* *}$ & $.41^{* *}$ & $.46^{* *}$ & .21 & -- & \\
6. Total Outness & $.91 * *$ & $.92^{* *}$ & $.67 * *$ & .11 & $.50^{* *}$ & -- \\
\hline
\end{tabular}

Note. ${ }^{* *} \mathrm{p}<.01$ 
expectations." Higher scores reflect greater satisfaction. Internal consistency was high for this measure $(\alpha=.92)$ and slightly higher than internal consistency estimates of past research $(\alpha=.86 ;$ Hendrick, 1988). Past research has also found good test-retest reliability (.85) for this measure (Hendrick, Dicke \& Hendrick, 1998). Scoring involved summing the 7 item ratings to produce a single relationship satisfaction score.

Demographic Questionnaire. The demographic questionnaire contained items asking about participants' age; educational level; sexual orientation; city of residence; occupation; race/ethnicity; income level; length of relationship; relationship status; living status; number of children; whether children were biological/adopted/step-children; whether children were from a previous relationship or from the present one; whether participants were in therapy or not; and how they heard about the study (see Appendix L). 


\section{CHAPTER III}

\section{Results}

\section{Preliminary Analyses}

Hierarchical multiple regressions were planned in order to predict the criterion variables of intrusiveness, closeness-caregiving and relationship satisfaction from the independent variables of age, attachment style, social support and outness. First, assumptions of linearity, normality and homoscedasticity were evaluated through SPSS Frequencies and examination of residual scatterplots. Most of these assumptions were not seriously violated, and when they were square-root and log transformations were performed on the relevant variables. However, when regression analyses using transformed variables were compared to regression analyses using non-transformed variables, there were very few differences between the two. For this reason, as well as for ease and accuracy of interpretation, only analyses using the regular, non-transformed variables have been reported.

Second, following standard practice for research in this field, the attachment style variable was dummy coded once to produce secure, fearful and preoccupied vectors, and another time to produce secure, fearful and dismissing vectors. In this way, all four of the attachment variables were converted to continuous variables that could be tested in the regression analyses. Finally, intercorrelations among predictor and criterion variables were examined to determine which of the predictor variables should be included in the regression analyses.

Order of variable entry into the regression equations was pre-determined based on theoretical considerations. It was reasoned that variables such as age and attachment style begin to impact the individual from a very early stage in life, compared to social factors 
such as social support and outness, which often develop at a later stage. Therefore, age and attachment variables were always entered before social support and outness variables. Main Analyses

Descriptive Statistics and Intercorrelations. Descriptive statistics for all predictor and criterion variables are presented in Table 3 . Note that Table 3 also includes descriptive statistics for the 9 subscales of the intrusiveness and closeness-caregiving dimensions. These subscale descriptives may provide a clearer picture of how most women scored on intrusiveness and closeness-caregiving behaviours than the $\mathrm{Z}$ scores for the combined intrusiveness and closeness-caregiving variables.

Sixty-six percent of the women were classified as having a secure attachment style; $21 \%$ were classified with a preoccupied attachment style; $9 \%$ had a dismissing attachment style; and $4 \%$ were classified as having a fearful attachment style. Table 4 presents the intercorrelations among predictor and criterion variables. The following discussion of these intercorrelations will focus only on the relationships relevant to conducting the main regression analyses. Regarding relationships between the predictor variables and intrusiveness, intrusiveness was significantly correlated with age, as well as with secure and preoccupied attachments. Therefore, these variables were included in the regression analyses. Contrary to my expectations, outness and social support did not have significant simple correlations with intrusiveness. However, because the alpha levels for social support $(p=.077)$ and outness $(p=.067)$ approached significance, I included these variables in the regression analyses predicting intrusiveness. As should be noted, there was a moderately high and statistically significant negative correlation between the secure and preoccupied attachment styles. Because of this relatively strong correlation, when 
Table 3

Means, Standard Deviations, and Range of Responses for Predictor and Dependent Variables

\begin{tabular}{|c|c|c|c|c|c|}
\hline Variable & $N$ & $M$ & $S D$ & $\begin{array}{l}\text { Sample } \\
\text { Range }\end{array}$ & $\begin{array}{l}\text { Scale } \\
\text { Range }\end{array}$ \\
\hline Social Support & 76 & 39.16 & 10.52 & $10-56$ & $8-56$ \\
\hline Outness & 76 & 82.18 & 21.41 & $22-108$ & $12-108$ \\
\hline Closeness-caregiving & 74 & 01 & .83 & $-3.03-.86$ & NA \\
\hline Warmth & 75 & 12.83 & 1.61 & $6.67-14$ & $0-14$ \\
\hline Time Together & 76 & 12.92 & 1.71 & $5.33-14$ & $0-14$ \\
\hline Nurturance & 75 & 12.87 & 1.40 & $6.33-14$ & $0-14$ \\
\hline Physical Intimacy & 76 & 12.23 & 1.67 & $6.33-14$ & $0-14$ \\
\hline Consistency & 75 & 11.55 & 2.27 & $4-14$ & $0-14$ \\
\hline Intrusiveness & 75 & -.01 & .71 & $-1.64-2.22$ & NA \\
\hline Separation Anxiety & 76 & 3.18 & 2.09 & $0-10$ & $0-14$ \\
\hline Possessiveness-Jealousy & 75 & 1.75 & 1.94 & $0-9.33$ & $0-14$ \\
\hline Emotional Interreactivity & 76 & 5.39 & 2.03 & $.67-10.67$ & $0-14$ \\
\hline Projective Mystification & 76 & 4.52 & 1.69 & $.67-9$ & $0-14$ \\
\hline Relationship Satisfaction & 77 & 30.27 & 5.45 & $13-35$ & $7-35$ \\
\hline
\end{tabular}


Table 4

Intercorrelations among Predictor and Dependent Variables

\begin{tabular}{|c|c|c|c|c|c|c|c|c|c|c|}
\hline Variable & 1 & 2 & 3 & 4 & 5 & 6 & 7 & 8 & 9 & 10 \\
\hline 1. Age & - & & & & & & & & & \\
\hline 2. Secure Attachment & .15 & - & & & & & & & & \\
\hline 3. Fearful Attachment & $-.18-$ & $-.28 *$ & -- & & & & & & & \\
\hline 4. Preoccupied Attachment & $-.16-$ & $-.72 *$ & -.10 & -- & & & & & & \\
\hline 5. Dismissing Attachment & .11 & $-.44 * *$ & $*-.06$ & -.16 & - & & & & & \\
\hline 6. Social Support & .03 & $.37 * *$ & -.09 & -.15 & $-.34^{* *}$ & -- & & & & \\
\hline 7. Outness & $.25^{*}$ & .19 & -.01 & -.17 & -.07. & $.36 * *$ & - & & & \\
\hline 8. Intrusiveness & $-.34 * *$ & $-.31 * *$ & $* * .12$ & $.35^{*}$ & $*-.08$ & .21 & -.21 & - & & \\
\hline 9. Closeness-caregiving & -.04 & .22 & -.15 & .12 & $-.47 * *$ & $.24 *$ & $.34 * *$ & -.13 & - & \\
\hline 10. Relationship Satisfaction & .01 & $.23^{*}$ & $-.26^{*}$ & .10 & $-.35^{* *}$ & .12 & .19 & -.06 & $.76 * *$ & -- \\
\hline
\end{tabular}

Note. ${ }^{*} \mathrm{p}<.05 .{ }^{* *} \mathrm{p}<.01$ 
these variables were entered into the same block of the regression model predicting intrusiveness there was a suppressor effect. This suppressor effect will be discussed in further detail when the results of the regressions predicting intrusiveness are discussed.

Regarding relationships between the predictor variables and closeness-caregiving, closeness-caregiving showed significant correlations with dismissing attachment, social support, and outness. Although I had not expected outness to be related to closenesscaregiving, because of the significant correlation between these two variables, outness was included with the other variables in the regression analyses. The simple correlations of secure, preoccupied, and fearful attachments with closeness-caregiving were not significant. These findings failed to provide preliminary support for my expectations that having a secure or preoccupied attachment style would be associated with showing high levels of closeness-caregiving, and that having a fearful attachment style would be associated with showing low levels of closeness-caregiving. However, because the correlation between secure attachment and closeness-caregiving approached significance $(p=.057)$, and therefore could be affected by partialling out other related variances, the secure attachment variable was included in the regression predicting closenesscaregiving.

It is important to note that although the correlations between variables of social support and outness, and between the secure and dismissing attachment variables were significant there was no evidence of multi-collinearity (indicated by Tolerance and Variance Inflation Factor statistics) on these variables when they were entered into the final regressions. 
Predicting Intrusiveness. I expected that intrusiveness in relationships would be predicted by age, attachment, social support and outness. Specifically, I hypothesized that women who were younger, women with a preoccupied attachment, women who perceived less social support from friends and family, and women who were less out to social networks would show greater intrusiveness in their lesbian relationships. For this regression model, age was entered into the first block, attachment variables into the second block, and social support and outness variables into the third block.

As mentioned before, a suppressor effect was exhibited when the secure and preoccupied attachment variables were entered into the same block of the regression model. This resulted in the model for the attachment variables being statistically significant $(F$ change $(2,70)=4.33, p=.017)$, but the unstandardized coefficients (or $B$ weights) for each of the secure $(B=-.10, t=-.66, p=.510)$ and preoccupied variables ( $B$ $=.24, t=1.55, p=.126$ ) being non-significant. Upon close inspection however, the correlation between preoccupied attachment and intrusiveness was slightly higher than that between secure attachment and intrusiveness (see Table 2), and the significance level of the $B$ weight for preoccupied attachment was closer to statistical significance than that of the $B$ weight for secure attachment. Therefore, I concluded that the secure variable might have enhanced the predictive ability of the preoccupied variable, by suppressing the variance that was irrelevant to the prediction of intrusiveness. Because this reasoning also matched my hypothesis that a preoccupied attachment would predict intrusiveness, I performed the final regression on intrusiveness using only the preoccupied variable in the second block.

A summary of the results of this regression is presented in Table 5. Results showed that the four variables accounted for $23 \%$ total variance in the prediction of intrusiveness. 
Table 5

Hierarchical Regression Analysis Summary for Age, Attachment, Social Support and

Outness Variables Predicting Intrusiveness $(N=77)$

\begin{tabular}{lcccccc}
\hline Variable & $B$ & $S E B$ & $\beta$ & $s r^{2}$ & $R^{2}$ & $\Delta R^{2}$ \\
\hline Step 1 & & & & & $.11^{*}$ & \\
Age & -.02 & .01 & $-.34^{*}$ & .07 & & \\
Step 2 & & & & & $.21^{*}$ & $.10^{*}$ \\
Preoccupied Attach. & .54 & .19 & $.31^{*}$ & .07 & & \\
Step 3 & & & & & .23 & .02 \\
Social Support & -.01 & .01 & -.14 & .02 & & \\
Outness & -.002 & .004 & -.05 & .002 & & \\
\hline$* p<.05$ & & & & &
\end{tabular}


By itself, age significantly accounted for $11 \%\left(R^{2}=.11, S E=.68\right.$; adjusted $\left.R^{2}=.10\right)$ of the variance in intrusiveness $(F(1,72)=9.19, p=.003)$. Thus, a one unit decrease in intrusiveness was significantly associated with a .02 increase in age $(B=-.02, S E B=.01$, $p=.003$ ). Examination of the $\beta$ weights indicated that age contributed the most variance of all predictor variables to the prediction of intrusiveness $(\beta=-.34 ; r=-.34, p=.002)$. More specifically, a one standard deviation decrease in intrusiveness was significantly associated with a .34 standard deviation increase in age. Squared semipartial correlations revealed that age uniquely contributed approximately $7 \%\left(s r=-.26, s r^{2}=.07\right)$ of the total variance in intrusiveness.

With age controlled, a preoccupied attachment style significantly accounted for another $10 \%\left(R^{2}=.21, S E=.65\right.$; adjusted $\left.R^{2}=.18\right)$ of the variance in intrusiveness $(F$ change $(1,71)=8.29, p=.005)$. Specifically, after controlling for age, a one unit increase in intrusiveness was significantly associated with a .54 increase in preoccupied attachment $(B=.54, S E B=.19, p=.005)$. Moreover, a one standard deviation increase in intrusiveness was significantly associated with a .31 standard deviation increase in preoccupied attachment $(\beta=.31 ; r=.35, p=.001)$. Squared semipartial correlations showed that preoccupied attachment uniquely contributed approximately $7 \%(s r=.27$, $\left.s r^{2}=.07\right)$ to the total variance in intrusiveness. These findings supported my hypothesis that having a preoccupied attachment style would significantly contribute to the prediction of intrusiveness in lesbian relationships, such that women with a preoccupied attachment style would show greater intrusiveness than would women of other attachment styles.

Social support and outness together accounted for another $2 \%\left(R^{2}=.23, S E=.64\right.$; adjusted $R^{2}=.19$ ) of the total variance in intrusiveness, after age and attachment. 
However, their contributions were not statistically significant $(F$ change $(2,69)=1.12, p$ $=.333)$. This finding indicates that neither social support nor outness contributed any additional variance to the prediction of intrusiveness once age and attachment had been factored in. Thus, my hypothesis that social factors such as social support and outness would significantly contribute to the prediction of intrusiveness was not supported. Finally, all four variables (age, preoccupied attachment, social support, and outness) together contributed $7 \%$ shared variance to the total variance in intrusiveness.

Predicting Closeness-Caregiving. I hypothesized that closeness-caregiving would be significantly predicted by attachment and social support, such that women with secure or preoccupied attachment styles, and women who perceived greater support from friends and family would show greater closeness-caregiving in their lesbian relationships. I also expected that women with dismissing and fearful attachment styles would show less closeness-caregiving. For this regression model, attachment variables were entered into the first block, and social support and outness variables were entered into the second block.

A summary of the results of this regression is presented in Table 6. Results showed that the four variables accounted for $32 \%$ total variance in the prediction of closenesscaregiving. Secure and dismissing attachments together significantly accounted for $22 \%$ $\left(R^{2}=.22, S E=.74 ;\right.$ adjusted $\left.R^{2}=.19\right)$ of the total variance in closeness-caregiving $(F(2$, $70)=9.96, p=.000$ ). However, upon examination of the coefficients, only the dismissing attachment variable was found to contribute significantly to the prediction of closenesscaregiving. Specifically, a one unit decrease in closeness-caregiving was associated with a 1.33 increase in a dismissing attachment $(B=-1.33, S E B=.34, p=.000)$. Moreover, a one standard deviation decrease in closeness-caregiving was associated with a .46 
Table 6

Hierarchical Regression Analysis Summary for Attachment, Social Support, and Outness

Variables Predicting Closeness-Caregiving $(N=77)$

\begin{tabular}{lrrrrrr}
\hline \multicolumn{1}{c}{ Variable } & $B$ & $S E B$ & $\beta$ & $s r^{2}$ & $R^{2}$ & $\Delta R^{2}$ \\
\hline Step 1 & & & & & $.22^{*}$ & \\
Secure Attach. & .03 & .20 & .02 & .001 & & \\
Dismissing Attach. & -1.33 & .34 & $-.46^{*}$ & .17 & & $.32^{*}$ \\
Step 2 & & & & & & $.10^{*}$ \\
Social Support & -.001 & .01 & -.02 & .00 & & \\
Outness & .01 & .004 & $.32^{*}$ & .09 & & \\
\hline
\end{tabular}

${ }^{*} p<.05$ 
standard deviation increase in a dismissing attachment $(\beta=-.46 ; r=-.47, p=.000)$. Therefore, although I did not obtain support for my hypotheses that a secure attachment would significantly predict closeness-caregiving, I obtained support for my hypothesis that a dismissing attachment would significantly predict closeness-caregiving. Specifically, I found that women with dismissing attachments demonstrated significantly less closeness-caregiving in their relationships. Furthermore, squared semipartial correlations indicated that a dismissing attachment uniquely contributed $17 \%$ to the total variance in closeness-caregiving $\left(s r=-.41, s r^{2}=.17\right)$. This was the greatest unique contribution of all variables.

With attachment variables controlled, social support and outness significantly accounted for another $10 \%\left(R^{2}=.32, S E=.70\right.$; adjusted $\left.R^{2}=.28\right)$ of the total variance in closeness-caregiving ( $F$ change $(2,68)=4.90, p=.010)$. However, in this block only the outness variable was significantly associated with closeness-caregiving. Thus, a one unit increase in closeness-caregiving was significantly associated with a .01 increase in outness $(B=.01, S E B=.004, p=.004)$. Moreover, a one standard deviation increase in closeness-caregiving was significantly associated with a .32 standard deviation increase in outness $(\beta=.32 ; r=.34, p=.002)$. Squared semipartial correlations showed that outness uniquely contributed approximately $9 \%\left(s r=.30, s r^{2}=.09\right)$ to the total variance in closeness-caregiving. Thus, my hypothesis that social support would significantly predict closeness-caregiving was not supported. However, unexpectedly, I found outness to be a significant predictor of closeness-caregiving, such that greater outness was related to greater closeness-caregiving. Finally, all four variables (secure and dismissing attachment, social support and outness) together contributed $6 \%$ shared variance to the total variance in closeness-caregiving. 
Predicting Relationship Satisfaction. One outlier case on the relationship satisfaction variable was detected, with an almost significant influence on the distribution (DFFIT = 1.75), and so this case was excluded from this set of regression analyses. I expected that closeness-caregiving rather than intrusiveness would significantly predict and be positively associated with relationship satisfaction. This hypothesis was supported: closeness-caregiving significantly accounted for $64 \%\left(\mathrm{R}^{2}=.64, \mathrm{SE}=3.3\right.$; adjusted $\mathrm{R}^{2}=$ $.64)$ of the variance in relationship satisfaction $(F(1,71)=128.46, p=.000)$. Moreover, a one unit increase in satisfaction was significantly associated with a 5.6 increase in closeness-caregiving $(\mathrm{B}=5.62, \mathrm{SE} \mathrm{B}=.50, \mathrm{p}=.000)$. As well, a one standard deviation increase in relationship satisfaction was associated with a .8 standard deviation increase in closeness-caregiving $(\beta=.80 ; r=.76, p=.000)$.

\section{Post-hoc Analyses}

Post-hoc analyses were conducted to examine whether intrusiveness and closenesscaregiving were correlated with any participant demographic factors. The factors that were examined included length of relationship, ethnicity, education level, income level, number of children, and whether participants lived with partners and children. No significant correlations were obtained between any of these variables and variables of intrusiveness and closeness-caregiving.

Correlation analyses were also conducted to examine whether discrepancies between participants and their partners on characteristics of age, ethnicity, sexual orientation, education, employment status, and income level were correlated with intrusiveness and closeness-caregiving. However, no significant correlations were obtained between any of the participant-partner discrepancies and variables of intrusiveness and closenesscaregiving. 
Finally, a population chi-square test was conducted to compare the ethnic composition of this study's sample to that of the general population of Ontario in $2001^{2}$. No significant difference was found $\left(\chi^{2}(5, N=77)=6.29, p=.28\right)$, suggesting that the proportions of women of various ethnicities in this sample were comparable to those in the greater population of Ontario.

${ }^{2}$ Ethnic diversity statistics were obtained from the Statistics Canada website. Ontario was used as a comparison group, because most women in this study's sample lived in Ontario. Statistics for 2001 were the most recent statistics provided by Statistics Canada. For the purposes of the population chi-square test only, the 2 women who indicated a mixed ethnicity of Caucasian and Jewish were coded as Caucasian, and the one woman who indicated a mixed ethnicity of Caucasian and Aboriginal was coded as Aboriginal. 


\section{CHAPTER IV}

\section{Discussion}

Traditional psychoanalytic theories that have equated separateness and autonomy with psychological maturity (e.g. Erikson, 1959; Mahler, 1975) have biased the way many researchers and clinicians, today, think about closeness in romantic relationships. Although less strictly adhered to now than in previous times, the influence of such theories in the field of psychology have resulted in the pathologizing of women's tendencies to desire higher levels of intimacy in their relationships and their greater capacities to be dependent on their romantic partners than men's.

Fusion, as a dynamic that involves very intense levels of closeness between partners and that may result in a loss of sense of personal autonomy, is one pattern of closeness in relationships that has been typically portrayed as completely dysfunctional (Karpel, 1976). Because conceptualizations of fusion have stemmed mainly from research with and observations of heterosexual couples, when such conceptualizations have been applied to lesbian relationships, they have served only to further stigmatize these relationships by pathologizing the high levels of intimacy that have been reported to exist between lesbian partners (Krestan \& Bepko, 1980).

More recently however, some researchers and clinicians have assumed a more positive perspective on fusion in lesbian relationships (Biaggio et al., 2002; Igartua, 1998; Mencher, 1990). Early theories about closeness and boundaries in family and romantic relationships (e.g. Minuchin, 1974) have been criticized for failing to clearly distinguish between positive and negative behaviours (Green \& Werner, 1996). Therapists and researchers alike have been urged to avoid pathologizing high levels of closeness in lesbian relationships simply because these patterns of closeness may deviate from 
traditional heterosexual norms, which often stipulate that healthy relationships should consist of a stereotypically male-female balance of autonomy and dependency (Biaggio et al., 2002; Igartua, 1998). Thus, fusion has been suggested to represent a natural and adaptive dynamic that may be unique to and beneficial for lesbian relationships (Burch, 1985; Greene et al., 1999; Mencher \& Slater, 1991).

Following this more recent line of research, the current study proposed a theoretical re-conceptualization of fusion, in which fusion was suggested to consist of positive as well as negative dimensions, which were defined as closeness-caregiving (warmth, time together, nurturance, physical intimacy, consistency) and intrusiveness (separation anxiety, possessiveness/jealousy, emotional interreactivity, and projective mystification) respectively (Werner \& Green, 1999). Additionally, the current study examined how these patterns of positive and negative fusion might be associated with developmental factors such as age and adult attachment, social factors such as social support and outness, as well as perceptions of relationship satisfaction.

Regarding adult attachment, Bartholomew's (1990) typology was used, which classifies people into secure, preoccupied, fearful or dismissing attachment styles. People with a secure attachment style have high self-esteem and reflect healthy attachments with others, being generally comfortable with both intimacy and autonomy in their relationships (Bartholomew \& Horowitz, 1991). Preoccupied, fearful and dismissing attachment styles are generally considered as insecure attachments. People with a preoccupied attachment tend to be overly dependent, hypervigilant, and easily jealous in their close relationships (Bartholomew, 1990; Buunk, 1997; Sharpsteen \& Kirkpatrick, 1997). People with a fearful attachment style tend to avoid intimacy in their relationships with others, due to the fear of being rejected (Bartholomew \& Horowitz, 1991). People 
with a dismissing attachment tend to also avoid close relationships, because they perceive themselves as self-reliant and not needing intimate relationships with others (Bartholomew \& Horowitz, 1991).

Most women in this study showed very high levels of positive fusion and very low levels of negative fusion toward their partners. Moreover, women who showed higher levels of positive fusion reported greater satisfaction in their relationships. These findings are consistent with what has been reported in past literature for levels of intimacy and satisfaction in lesbian relationships (Eldridge \& Gilbert, 1990; Greene et al., 1999; Kurdek \& Schmitt, 1986; Mencher, 1984; Peplau et al., 1978; Schreurs \& Buunk, 1995, 1996; Zacks et al., 1988). Interestingly, positive fusion contributed more than $60 \%$ to the prediction of relationship satisfaction in this study. This finding is quite dramatic and emphasizes the need to recognize that lesbian partners may place great value on establishing high levels of closeness with each other, because they regard and experience high levels of closeness as satisfying and beneficial.

This study suggested that, in general, developmental variables such as age and attachment are better predictors of negative and positive fusion than social variables such as social support and outness. In order to appreciate the implications of this finding it is necessary first to discuss the specific relationships of these developmental and social variables to positive and negative fusion. In terms of the relationship between age and fusion, findings were consistent with past research (Greene et al., 1999; Hornstein, 1996). As expected, older women demonstrated less negative fusion in their relationships than younger women. This finding might be explained by Greene et al.'s (1999) speculation that, because younger women may not have as many external support systems as older women, younger women might be more likely to rely on their relationships as their only 
source of validation and support, and therefore might become more fused with their partners than older women. This explanation therefore attributes the relationship between age and fusion to systems theory (Krestan \& Bepko, 1980).

However, Greene et al.'s (1999) conceptualization of fusion failed to explicitly differentiate between what could have been positive and negative types of fusion. Thus, although in the current study it was clear that age was related to negative fusion and was not related to positive fusion, it was not clear in Greene et al's (1999) study to which type of fusion age was related. Because of this lack of clarity in previous studies and as a result of the current study's findings, perhaps systems theory explanation for the relationship between age and fusion in lesbian relationships should be revised to make it explicit that lack of external social support against society's homophobic reactions contributes to only negative types of fusion, and not positive types of fusion in lesbian relationships.

This study might also suggest however, that systems theory is not an entirely accurate explanation for the relationship between age and negative fusion. For instance, contrary to systems theory explanation, this study did not find that women who were older had significantly more external social supports than women who were younger. As an alternative explanation I would point to the developmental influence that age might have on negative fusion. Fusion might be less likely to occur as women grow older, because women might be better able to assert and enjoy their individuality as they mature. It may also be reasoned that as women grow older and as more time goes by in their relationships, they might feel more secure and comfortable in their relationships and with their partners. Thus, notions of and issues surrounding physical and emotional separation from partners may feel less threatening and anxiety provoking to women who are older. However, this latter explanation should be accepted with caution because the current 
study did not find that negative fusion significantly decreased as women's relationships grew longer. Hence, further replication of these findings, particularly in longitudinal studies, may be needed in order to draw firmer conclusions about why negative fusion is less likely to occur with older women regardless of length of relationship.

In the field of attachment, Bartholomew's (1990) fearful and dismissing attachments can be paralleled to Hazan and Shaver's (1987) avoidant attachment style. Likewise, Bartholomew's (1990) preoccupied attachment style can be compared to Hazan and Shaver's (1987) anxious-ambivalent attachment style. This study found that, relative to other attachment styles, having a dismissing attachment was associated with showing lesser positive fusion in relationships, and that having a preoccupied attachment style was associated with showing greater negative fusion in relationships. These findings are consistent with past research suggesting that an anxious-ambivalent attachment would be and was related to greater intrusiveness (Green \& Werner, 1996; McBain, 2000), and that an avoidant attachment would be and was related to lesser closeness-caregiving and greater fear of intimacy in relationships (Green \& Werner, 1996; Greenfield \& Thelen, 1997).

The finding for dismissing attachment was expected given that people with dismissing attachments tend to avoid intimacy with others. The finding for preoccupied attachment was also expected given that some of the behaviours reflective of negative fusion (e.g. separation anxiety, possessiveness/jealousy) are very similar to some of the behaviours associated with having a preoccupied attachment. The positive relationship between preoccupied attachment and negative fusion was further validated by the finding that secure attachment was inversely correlated with negative fusion. Given that secure and preoccupied attachments are themselves inversely correlated, it makes complete sense 
that if women with preoccupied attachments show greater negative fusion in their relationships, then women with secure attachments would show lesser negative fusion in their relationships.

Surprisingly however, the expectation that having a secure attachment would be associated with greater positive fusion was not supported. This was inconsistent with Green and Werner's (1999) suggestion that a secure attachment might be associated with higher levels of closeness-caregiving. However, it is noteworthy that the simple correlation between secure attachment and positive fusion was in the expected direction and also approached statistical significance. It is therefore possible to attribute the lack of statistical significance to the fact that most women reported high levels of positive fusion with very little variation among them. Thus, the relationship between secure attachment and positive fusion might have been statistically significant had there been greater variability in responding on the positive fusion dimension.

Another possible explanation is that although having a more secure attachment is related to showing lesser negative fusion in relationships, it is not necessarily related to showing greater positive fusion. This explanation postulates then that positive and negative types of fusion do not lie on the same continuum and as such are not opposite forms of closeness. Thus, the absence of negative fusion does not imply the presence of positive fusion, and the absence of positive fusion does not imply the presence of negative fusion. This reasoning supports the very basis of the current study that positive and negative types of closeness should be considered as distinct and separate dimensions (Green \& Werner, 1996). Finally, the lack of association between secure attachment and positive fusion might also be explained by other personal or relationship factors, which have not been taken into account in this study, and which might be attenuating the 
tendencies of women with secure attachment styles to show positive form of fusion in their relationships.

Given that a fearful attachment is also considered an avoidant style of relating to others, it was surprising not to find that women with a fearful attachment showed lesser positive fusion in their relationships. Although the simple correlation between fearful attachment and positive fusion was in the expected direction it was not statistically significant, and so it was not appropriate to include the fearful attachment variable in the final regression analysis. Given that the proportion of women with a fearful attachment in this study (4\%) is somewhat lower than the proportions of women with fearful attachment styles reported in past literature (21\% in Bartholomew \& Horowitz; $30 \%$ in Canon, 1999), it is possible that the lack of a significant relationship between fearful attachment and positive fusion was due to insufficient statistical power. Thus, this finding may need to be replicated with a sample of women having a larger proportion of women with a fearful attachment before valid conclusions can be drawn about its meaning. These findings might suggest however, that although people with fearful and dismissing attachments both tend to avoid closeness and may also avoid relationships altogether, the avoidance might be lesser for those with a fearful attachment than for those with a dismissing attachment. This explanation might be especially feasible given that, unlike people with dismissing attachments, people with fearful attachments often still desire to have intimate relationships with others (Bartholomew \& Horowitz, 1991).

The current study also did not find, as expected, that women with a preoccupied attachment would show levels of positive fusion comparable to women with secure attachments, and higher than women with fearful and dismissing attachments. It seemed reasonable to surmise that because having a romantic relationship is very important to 
people with preoccupied attachments, they would show levels of warmth, nurturance, and physical intimacy comparable to that of secure women. However, my lack of findings for this association might provide support for McBain's (2000) suggestion that, although, people with anxious attachment styles place a high value on being in a relationship, their experiences within relationships tend to be predominantly negative and stressful, and when under stress their behaviour patterns tend to be maladaptive. Hence, the patterns of closeness that preoccupied women show in their relationships may be predominantly dysfunctional.

In general, social factors such as social support and outness were not related to negative and positive fusion in the expected ways. After age and attachment were taken into account, neither social support nor outness was predictive of negative fusion. The lack of relationship between social support and negative fusion was inconsistent with the findings of past research (Hornstein, 1996). However, the lack of relationship between outness and negative fusion was consistent with Roper's (1997) finding that outness was not related to intrusiveness. Social support was also not related to positive fusion and this was consistent with past findings (Roper, 1997).

Unexpectedly however, this study found that outness was a significant predictor of positive fusion even after attachment was taken into account. Thus, women who were more out showed greater positive fusion behaviours in their relationships. It may be that, in general, women who are more out are more self-accepting, and are happier in their relationships because they do not have to deal with the stresses of being closeted. This would be consistent with Jordan and Deluty's (1998) finding that women who were more out had higher self-esteem and less anxiety. As a result, such women might be more inclined to show positive fusion behaviours toward their partners. It may also be that 
women who are more out are more physically demonstrative and emotionally intimate with their partners because they do not have the same fear of discovery or judgment of their sexual orientation as do women who are more closeted.

Another explanation for the relationship between outness and positive fusion is that in this study the construct of outness may have been conceptually similar to the construct of social support. For instance, one of the outness items read "those that know I am a lesbian are supportive of this." Indeed this explanation would be consistent with Jordan and Deluty's (1998) finding that higher levels of outness were related to greater perceived social support. However, in the present study, the kind of support assessed by the outness measure was different to the kinds of social support assessed by the social support measure. Thus, whereas the social support measure assessed support received from social networks mainly during times of need, the outness measure assessed support received for one's sexual identity. Hence, it may be that for lesbians and bisexual women, receiving validation and support for their sexual identity is a more important form of social support and as such has greater influence on their tendencies to show positive fusion than do other kinds of social support, such as support in time of need. This conclusion might support Wayment and Peplau's (1995) finding that lesbians' psychological well-being was most significantly influenced by reassurance of worth, which is defined as social support that provides a sense of competence and the feeling that one is appreciated for one's abilities and social roles (Weiss, 1974).

Altogether, the results of this study suggest that the developmental factors of age and adult attachment were more powerful predictors of positive and negative fusion than were the social factors of social support and outness. It may be that because the psychological dispositions and behaviours that result from one's attachment style are formed early in a 
one's life and are therefore more deeply ingrained, these have a greater impact on one's relationship behaviours than do social or external factors. Indeed, this reasoning makes sense in light of the notion that people's infant attachment styles remain relatively stable throughout their lives, forming the basis for their adult attachment styles, and therefore influencing to a great extent the way they behave in their romantic relationships (Hazan \& Shaver, 1987). It may also be that age is a better predictor of negative fusion than social factors because chronological age determines level of psychosocial development, and level of psychosocial development is a better predictor of how a person will perceive and behave in her relationships with others than social factors.

It is important however to recognize that although social factors did not generally contribute as much as age and attachment style to the prediction of positive and negative fusion, some social factors such as outness still showed a significant relationship to positive fusion. This finding might suggest that regardless of one's attachment style or age, greater outness is related to greater positive fusion. Additionally, there may be other social factors, not examined in this study that would influence positive or negative fusion. It is therefore important not to completely discount the influence of social factors on women's tendencies to show positive or negative fusion in their relationships.

\section{Theoretical Implications}

The current study adds to the base of recent literature that directly counters the negatively biased manner in which early literature has portrayed fusion in lesbian relationships. Not only have these early depictions labelled fusion as a completely dysfunctional state, but they have also suggested that dysfunctional fusion occurs more frequently in lesbian relationships than in heterosexual relationships (Berg-Cross, 1988; Krestan \& Bepko, 1980; Pearlman, 1989). While I cannot draw any comparisons to 
heterosexual relationships in this study, I can assert that the majority of women in this study did not demonstrate high levels of negative fusion and actually demonstrated very high levels of positive and healthy fusion. Thus, although lesbian partners may be so close to each other that individual boundaries may appear to be blurred or crossed, it is not always appropriate to label such intense closeness or such blurring of boundaries as dysfunctional. Thus, I have offered that the label "fusion" could be maintained and reclaimed to signify an often positive dynamic that occurs in lesbian relationships. However, I also suggest that when defining fusion it would be necessary to qualify it as being either positive or negative.

This study has provided empirical validation for some of Bartholomew's (1990) attachment styles. For example, consistent with what has been suggested in past literature (Brennan \& Shaver, 1995; Carnelly et al., 1994; Feeney \& Noller, 1991; Simpson, 1990), women with secure attachments reported greater relationship satisfaction than women with fearful and dismissing attachment styles. The present study has also extended the literature by relating Bartholomew's (1990) adult attachment styles to patterns of positive and negative fusion shown by lesbian partners. This extension supports McBain's (2000) findings, as well as past researchers' calls for more ties to be drawn between attachment theory and family dynamics (Strahan, 1991; Tordoski, 1995).

The finding that, in general, developmental factors had a stronger influence than social factors on a woman's tendencies to show either positive or negative fusion toward her lesbian partner holds important implications for existing theories about fusion in lesbian relationships. First, it suggests that systems theory may not explain the whole story regarding the occurrence of negative fusion in lesbian relationships. This study found that neither outness nor social support significantly predicted negative fusion 
beyond the contribution of age and attachment. Hence, it seems that the amount of support and validation a woman receives for her sexual orientation is not the only factor that determines whether or not she will be negatively fused with her partner. Existing theories for fusion in lesbian relationships therefore need to be expanded and advanced to take into account the potentially more powerful role of developmental factors such as age and attachment.

The role of age, in particular, should be considered important in defining and understanding the nature of negative fusion in lesbian relationships. The association between age and negative fusion has been found in at least three empirical studies examining lesbian relationships including the present study. Additionally, in a study of separation-individuation and young women's intimacy patterns, Levitz-Jones and Orlofsky (1985) found that in their sample of mostly first-year university women (aged 18-19 years, with no indication of sexual orientation) $60 \%$ had reported being fused with their partners. As a result, the authors suggested "it is quite likely that the intimacy styles and separation-individuation manifested by many of these young women represent developmental levels within a progression of psychological growth more than stable characterological positions at which they are fixed" (Levitz-Jones \& Orlofsky, 1985, p. 168). These findings all imply that if age is integrated into theories about negative fusion in lesbian relationships, then negative fusion may be seen as a transient state, which is partly due to a woman's temporary lack of psychological maturity and relationship experience rather than entirely to her psychosocial development as a woman and her capacities for autonomy and boundary differentiation. Viewing negative fusion in this manner would help researchers to avoid pathologizing women's relational tendencies. 
Another implication of this study concerns the issue of renaming versus reclaiming. Several authors in the past have suggested that if we are to re-define traditional notions of fusion in lesbian relationships by emphasizing positive aspects of fusion, then the label "fusion" should be no longer used (Greene et al., 1999; Mencher, 1990). Mencher (1990) claimed that it might be impossible to "de-toxify" (p. 325) the term fusion. This is because the term "fusion" has acquired such negative connotations in the psychological literature that any use of it might only serve to perpetuate negative and biased notions about its occurrence in lesbian relationships. Authors have suggested that terms such as “connectedness," commitment" (Greene et al., 1999) or "embeddedness" (Mencher, 1990) be used instead.

Despite these suggestions, I decided to maintain the use of the label fusion to denote positive and healthy patterns of intense intimacy in lesbian relationships. I did this for two reasons. First, it is a word that many researchers, clinicians, lesbians and bisexual women are familiar with. Hence, maintaining the use of it fosters understanding of the purpose of this study. Second, I wished to attempt to re-claim the meaning of fusion from its traditional, negatively typed definitions and implications. The results of this study suggested that lesbian couples are very satisfied with high levels of closeness in their relationships. These high levels of closeness may reflect some of the features of lesbian relationships described by Mencher (1990) (e.g., intense intimacy, acute awareness of the inner emotions of the other, and connection of individual identity to the relationship), which have been labelled as dysfunctional by early researchers and clinicians, because they do not conform to men's intimacy and identity development patterns. Thus, by using the word fusion to denote positive patterns of closeness I have suggested that fusion, as the process of two individuals becoming so highly attuned to each other that personal 
boundaries become embedded in the identity of the relationship, may not be a process that is harmful to women. Indeed, such a process may be reflective of unique, healthy and satisfying patterns of closeness among lesbian partners.

An important consequence of re-claiming fusion is that, as some feminist authors (e.g. Miller, 1991; Surrey, 1991) have argued, patterns of women's intimacy and identity development are viewed in a relational context. In this way, patterns of fusion in women's relationships can be regarded as both consequences of and paths to healthy female identity development. Today, these feminist views of fusion and women's identity development, although widely known, are still regarded as 'alternative' theories and remain on the fringes of accepted psychological theories for women's psychosocial development. I argue that, as a result of studies like mine, more efforts should be made to adopt such 'alternative' theories into the more mainstream views of human psychosocial development (e.g. Erikson, 1963), so that women's unique patterns of development are recognized and studied.

\section{Clinical Implications}

In 1985, McCandlish stated that because traditional heterosexual therapists might feel some discomfort with high levels of intimacy in lesbian relationships, they might be more likely to regard such relationship dynamics as immature or pathological. This kind of attitude on the part of therapists can contribute to a lesbian couple's separation (McCandlish, 1985). Certainly, in the two decades following this statement, the proliferation of literature on the nature and dynamics of same-sex relationships, as well as the growing acceptance of same-sex relationships in Canadian culture, have seemed to contribute to a greater awareness on the part of therapists of specific issues related to conducting therapy with lesbians, gay men, bisexual and transgendered/transsexual 
persons. However, it is unclear whether twenty years after McCandlish's (1985) statement attitudes among therapists toward fusion or toward intimacy in lesbian relationships have improved much.

Murphy (1992) called on therapists to explore the ways in which their own homophobia, heterosexism, and sexism might have an impact on the dynamics of the therapeutic relationship with lesbian couples. The present findings support this argument by calling on therapists who work with lesbian and bisexual women to avoid fitting lesbian relationships into a heterosexual mould of functioning. Instead, therapists are urged to become familiar with lesbian culture and ethics (Igartua, 1998), and specifically, with the ways in which patterns and levels of intimacy in lesbian relationships might be different from those in heterosexual relationships. Particular awareness of the differences between healthy and unhealthy patterns of closeness among lesbian partners will not only make therapists better equipped to counsel lesbian couples, but will also help therapists to avoid overlooking and pathologizing healthy intimacy in lesbian relationships. In this manner, therapists might recognize that sometimes, high levels of intimacy might reflect high degrees of love, trust and commitment between lesbian partners (Biaggio et al., 2002). As Igartua (1998) pointed out, "it appears that lesbians function comfortably at greater levels of [fusion] than heterosexual controls" (p. 394).

A final therapeutic implication lies in the recognition of how insecure attachment styles contribute to women's demonstrations of greater negative fusion and lesser positive fusion in their relationships. If therapists became more aware of these associations, they would be better able to understand why negative patterns of fusion might occur (McBain, 2000). Moreover, they would be able to explore how and why such insecure attachments 
were formed with caregivers, and point out for individuals and couples how those patterns of attachment might be played out in the romantic relationship.

Furthermore, recognition that women's early life experiences with their parents and other caregivers have an impact on their tendencies to display maladaptive patterns of fusion in their relationships, might help therapists to recognize that such patterns of fusion may also occur in the relationships of heterosexual women. Indeed, some research has found that heterosexual women displayed moderate levels of fusion in their relationships, equal to those of lesbians (Greene et al., 1999). In a society where homosexuality is so strongly condemned, it is important that fusion is not used as a reason to further pathologize and stigmatize the sexuality and relationships of bisexual women and lesbians.

\section{Limitations}

Some limitations to the present study must be acknowledged. The sample size was relatively small, possibly resulting in a lack of sufficient statistical power to produce significant results in some cases. Future research might therefore attempt to replicate the findings of this study with a larger sample. However, it is interesting that given the small sample size many important relationships were still found.

There was also reduced variability in responding on some measures. For instance, most women in the sample scored very high on measures of social support, outness, satisfaction, and closeness-caregiving. Also, the majority of women scored very low on intrusiveness. Moreover, for the dimensions of intrusiveness and closeness-caregiving in particular, standard deviations were small, suggesting that the range of responding may have been too restricted to produce statistically significant effects for some of the correlations and regressions. 
Additionally, although some attempts were aimed at recruiting women who might be closeted, there was the possibility that the sample was biased in this manner. As mentioned before, women in this sample generally reported very high levels of outness. Because outness is an important concern for many lesbians and bisexual women the sample may not have included many women from the population of hidden lesbians and bisexual women.

It is also quite possible that there was a self-selection bias in this sample, such that women who were happier and more satisfied in their relationships were more likely to participate in the study than women who were unhappy in their relationships. This could explain why most women scored high on health intimacy and low on unhealthy closeness, as well as why most women reported being highly satisfied with their relationships. Women who may not have wished to disclose information about their relationships that could be perceived as negative might not have participated in the study. Also, women who tend to show negative patterns of fusion in their relationships may have been less likely to be in a relationship for more than 3 months, and thus may not have qualified for the study. Such sampling issues may have limited the generalizability of my findings to the greater population of lesbians and bisexual women.

Moreover, the results of this study may have been influenced by issues of socially desirable responding and use of self-report measures. Because lesbians and bisexual women are typically discriminated against for their sexual orientation, it is possible that the women in my study feared such discrimination by the researcher, and so felt motivated to convey a favourable impression of themselves and their relationships. However, attempts were made to reduce this limitation through the researcher's identification in the cover letter, as a member of the group being studied. 
This study did not obtain a large proportion of women of non-Caucasian ethnicities. Thus, differences in fusion and attachment styles among various ethnic groups could not be adequately examined. Therefore, it must be acknowledged that this study's findings may not be entirely generalizable to the fusion dynamics or attachment styles of lesbians and bisexual women of ethnic minority backgrounds. Nevertheless, as the population chisquare test revealed, this study's sample can be considered a valid representation of the ethnic composition of Ontario's greater population.

Another limitation of this study pertains to attachment and fusion measures that were used. Although, both measures demonstrated high reliabilities, comparable to reliabilities for the heterosexual populations on which they were developed, it must be acknowledged that these measures have not been widely used and validated with lesbian and bisexual women populations. Furthermore, it is still unclear whether the relationships dynamics referred to in these measures are truly applicable to the dynamics of lesbian relationships. For example, although I used the CIFA to examine fusion behaviours in lesbian couples, it must be noted that the CIFA is not a purported measure of fusion in lesbian relationships.

Moreover, although the authors of the CIFA adapted the measure to be used with lesbian couples and have adequately distinguished between negative and positive closeness behaviours in relationships, it is still not clear whether what was postulated to refer to negative and positive closeness in heterosexual relationships (in the CIFA) applies to what might be labelled negative and positive closeness in lesbian relationships. The results of my research might suggest that these relationship dynamics do apply to lesbian relationships as well, however much more research is needed in order to further validate the use of the CIFA with lesbian and bisexual women. 
A final limitation pertains to independence of observations. It is possible that if my recruitment messages reached both partners of the same couple separately, then both partners might have unwittingly participated in the study. However, this was highly unlikely given that participants were explicitly instructed that their partners could not participate, and close comparisons of the demographic information did not reveal with any certainty that women's partners had also participated. Also, it was assumed that women would notify their partners of their participation, so that partners would not to take part in the study if they ended up also being recruited through snowballing or emails.

Though there were several limitations in this study, there were many methodological strengths. For instance, this study included women of different age groups, with diverse ethnic and cultural backgrounds, as well as varying educational levels and socioeconomic statuses. Also, there was a good response rate. Additionally, all measures were standardized and generally showed good reliabilities, consistent with what has been found in past research using these measures. Moreover, the fact that many significant relationships were found with a small sample size suggests that statistical effects were fairly large and meaningful. Furthermore, although it was necessary to acknowledge existing limitations in recruitment and methodology, it should be emphasized that many steps were taken to attempt to reduce these limitations wherever possible.

\section{Directions for Future Research}

In addition to improving on the limitations of this study described above, several other directions for future research exist. Researchers may wish to replicate and compare this study's findings to the relationships of heterosexuals and gay men, in order to update findings on whether differences in levels of healthy and unhealthy fusion actually exist among lesbian, heterosexual and gay male couples. Whereas early literature has 
suggested that lesbian couples report higher levels of negative fusion than heterosexual or gay male couples (Krestan \& Bepko, 1980), more recent research has not supported this claim (Colwell, 1988; Greene et al., 1999; Hornstein, 1996). However, some differences have been found. Lesbian couples have been found to report higher levels of healthy closeness (referred to as cohesion) (Zacks et al., 1988), emotional intimacy (Schreurs \& Buunk, 1995), and relationship satisfaction (Zacks et al., 1988) than heterosexual couples. Additionally, lesbian couples have reported less of a fear of intimacy than heterosexual women (Hornstein, 1996).

Furthermore, just as lesbian partners have been stereotyped as being fused in the early psychological literature, gay male partners have often been stereotyped as being disengaged or emotionally distant, more so than lesbian or heterosexual couples (Krestan \& Bepko, 1980). Although some research has refuted these claims by showing that gay male couples also report high levels of closeness, and sometimes even higher levels than lesbian and heterosexual couples (Colwell, 1988; Green et al., 1996), more research is needed to validate these comparisons and to counter the often negative stereotypes about levels of intimacy in same-sex relationships. Future research might also wish to examine whether findings for the specific relationships of attachment, social support, outness and satisfaction to negative and positive fusion in lesbian relationships are comparable to the relationships of gay males and heterosexuals as well.

Another avenue for future research might be to explore whether age effects on negative fusion still exist when lesbians and bisexual women are studied longitudinally. The results of cross-sectional comparisons, such as in this study, might be attributed to cohort effects. Longitudinal studies would not only be able to rule out a cohort effect, but also could explore exactly how and why patterns of negative fusion might decrease with 
age. Such studies would provide a better understanding of whether negative fusion might indeed be, in part, a developmental phenomenon. Related to this, is the need to also explore how other individual, social and relationship factors, besides the ones examined in this study, might relate to demonstrations of positive and negative fusion in lesbian relationships.

Additionally, future research might explore and compare the intimacy patterns of lesbians and bisexual women of diverse ethnic and cultural backgrounds. Cultural notions about intimacy, dependence, and autonomy in relationships may influence the fusion behaviours that lesbian partners demonstrate. Thus far, research in the area of fusion in lesbian relationships has been lacking in its specific exploration of ethnic minority women's intimacy beliefs and behaviours.

In a similar vein, although bisexual women in lesbian relationships may share similar sexuality and relationship issues as lesbians, it would be important for future researchers to explore whether there are any differences in the patterns of positive and negative fusion between bisexual women and lesbians. The current study was unable to examine such differences, because the proportion of bisexual women in the sample was too small. As Roper (1997) suggested however, if we do not separately examine bisexual women's relationship behaviours we run the danger of applying theories based on one group of women to a group of women on whom such theories were never specifically tested.

Future research might also wish to replicate this study's findings with a sample of couples instead of only individual partners. It is possible that couple reports would provide more accurate and reliable depictions of actual patterns of positive and negative fusion in lesbian relationships than individual reports. Future researchers should also explore how interactions between developmental and social factors might influence 
women's demonstrations of positive and negative types of fusion. For example, interactions between attachment and social support, or between attachment and outness might be explored. Examination of such interactions would provide interesting insight into whether social support and outness have an impact on the fusion for women whose attachment styles predispose them to show particular types of fusion.

Finally and perhaps most importantly, future researchers should attempt to develop a questionnaire that measures positive and negative fusion behaviours as they occur specifically in lesbian couples. Psychological research on the intimacy patterns of lesbian couples cannot be sufficiently advanced without a measure that has been developed solely on a model of lesbian relationships. In psychological research, heterosexual-centered theoretical models guide much of our knowledge about the dynamics of both heterosexual and same-sex relationships. We assume that what happens in heterosexual relationships also happens in same-sex relationships. Although this view might serve to protect samesex relationships from being regarded as abnormal because they deviate from the heterosexual norm, they might also serve to obscure or pathologize some of the behaviours and dynamics that are unique to same-sex relationships. Just as early feminist work has rejected comparing aspects of women's psychology to male-centered theories and models, so should researchers and clinicians recognize that same-sex relationships are not inferior or abnormal because they may be characteristically different from heterosexual ones. 
References

Ainsworth, M. D. S., Blehar, M. C., Waters, E., \& Wall, S. (1978). Patterns of attachment: A psychological study of the strange situation. Hillsdale, N. J.: Erlbaum.

Bartholomew, K. (1990). Avoidance of intimacy: An attachment perspective. Journal of Social and Personal Relationships, 7, 147-178.

Bartholomew, K., \& Horowitz, L. M. (1991). Attachment styles among young adults: A test of a four-category model. Journal of Personality and Social Psychology, 61(2), 226-244.

Bartholomew, K., \& Shaver, P. R. (1998). Methods of assessing adult attachment. In J. A. Simpson \& W. S. Rholes (Eds.). Attachment theory and close relationships (pp. 2545). New York: The Guilford Press

Beals, K. P., \& Peplau, L. A. (2001). Social involvement, disclosure of sexual orientation, and the quality of lesbian relationships. Psychology of Women Quarterly, $25,10-19$.

Beals, K. P., Impett, E. A., \& Peplau, L. A. (2002). Lesbians in love: Why some relationships endure and others end. Journal of Lesbian Studies, 6(1), 53-63.

Bepko, C., \& Johnson, T. (2000). Gay and lesbian couples in therapy: Perspectives for the contemporary family therapist. Journal of Marital and Family Therapy, 26(4), 409-419.

Berg-Cross, L. (1988). Lesbians, family process and individuation. Journal of College Student Psychotherapy, 3(1), 97-112.

Biaggio, M., \& Coan, S., \& Adams, W. (2002). Couples therapy for lesbians: Understanding merger and the impact of homophobia. Journal of Lesbian Studies, $6(1), 129-138$. 
Blyth, S., \& Straker, G. (1996). Intimacy, fusion and frequency of sexual contact in lesbian couples. South African Journal of Psychology, 26(4), 253-256.

Bowen, M. (1966). The use of family theory in clinical practice. Comprehensive Psychiatry, 7, 345-374.

Bowlby, J. (1973). Attachment and loss: Vol. 2. Separation. New York: Basic Books.

Bowlby, J. (1977). The making and breaking of affectional bonds. British Journal of Psychiatry, 130, 201-210.

Brehm, S. S. (1992). Intimate relationships (2nd ed.). New York: McGraw-Hill.

Brennan, K. A., \& Shaver, P. R. (1995). Dimensions of adult attachment, affect regulation, and romantic relationship functioning. Personality and Social Psychology Bulletin, 21, 267-283.

Brennan, K. A., Clark, C.L., \& Shaver, P.R. (1998). Self-report measures of adult romantic attachment: An integrative overview. In J. A. Simpson \& W. S. Rholes (Eds.), Attachment theory and close relationships (pp. 46-76). New York: Guilford.

Brown, L. S. (1996). Preventing heterosexism and bias in psychotherapy and counselling. In E. D. Rothblum \& L. A. Bond (Eds.), Preventing heterosexism and homophobia (pp. 36-57). Thousand Oaks, CA: Sage Publications.

Burch, B. (1982). Psychological merger in lesbian couples: A joint ego psychological and systems approach. Family Therapy, 9(3), 201-208.

Burch, B. (1985). Another perspective on merger in lesbian relationships. In L. B. Rosewater \& L. Walker (Eds.). Handbook of feminist therapy: Women's issues in psychotherapy. New York, N. Y.: Springer Publishing Company.

Burch, B. (1986). Psychotherapy and the dynamics of merger in lesbian couples. In T. Stein \& C. Cohen (Eds.). Contemporary perspectives on psychotherapy with lesbians 
and gay men (pp. 57-71). New York: Plenum Publishing.

Buunk, B. P. (1997). Personality, birth order and attachment styles as related to various types of jealousy. Personality and Individual Differences, 23, 997-1006.

Canon, B. (1999). Marriage and cohabitation: A comparison of adult attachment style and quality between the two types of relationships. (Doctoral Dissertation, California School of Professional Psychology, 1999). Dissertation Abstracts International, 60 (5-B), 2332. (UMI No. 9929405)

Carnelly, K. B., Pietromonaco, P. R., \& Jaffe, K. (1994). Depression, working models of others and relationship functioning. Journal of Personality and Social Psychology, $66,127-140$.

Caron, S. L., \& Ulin, M. (1997). Closeting and the quality of lesbian relationships. Families in Society: The Journal of Contemporary Human Services, 78, 413-419.

Cassidy, J., \& Kobak, R. (1988). Avoidance and its relation to other defensive processes. In J. Belsky \& T. Nezworksi (Eds.). Clinical implications of attachment. Hillsdale, N. J.: Lawrence Erlbaum.

Causby, V., Lockhart, L., White, B., \& Green, K. (1995). Fusion and conflict resolution in lesbian relationships. Journal of Gay and Lesbian Social Services, 3(1), 67-82.

Chodorow, N. (1978). The reproduction of mothering: Psychoanalysis and the sociology of gender. Berkeley: University of CA Press.

Cohen, K. M., \& Savin-Williams, R. C. (1996). Developmental perspectives on coming out to self and others. In R. C. Savin-Williams \& K. M. Cohen (Eds.). The lives of lesbians, gays, and bisexuals: Children to adults (pp. 113-151). Fort Worth, TX: Harcourt Brace College Publishers.

Cohen, S., \& Wills, T. A. (1985). Stress, social support, and the buffering hypothesis. 
Psychological Bulletin, 98, 310-357.

Cole, S. W., Kemeny, M. E., Taylor, S. E., \& Visscher, B. R. (1996). Elevated health risk among gay men who conceal their homosexual identity. Health Psychology, 15(4), 243-251.

Collins, N. L., \& Read, S. J. (1990). Adult attachment, working models, and relationship quality in dating couples. Journal of Personality and Social Psychology, 58, 644-663.

Colwell, J. B. (1988). Gender differences in levels of merging and disengagement in the intimate relationships of same-sex and opposite-sex couples. (Doctoral Dissertation, University of Colorado, 1988). Dissertation Abstracts International, 50(2-B), 743.

Eldridge, N., \& Gilbert, L. (1990). Correlates of relationship satisfaction in lesbian couples. Psychology of Women Quarterly, 14, 43-62.

Elise, D. (1986). Lesbian couples: The implications of sex differences in separationindividuation. Psychotherapy, 23, 305-310.

Erikson, E. (1959). Identity and the life cycle. Psychological Issues, 1, 1-171.

Feeney, J. A., \& Noller, P. (1990). Attachment style as a predictor of adult romantic relationships. Journal of Personality and Social Psychology, 58, 281-291.

Finch, T. M. (1999). Relationship satisfaction among lesbian couples: The effects of fusion and love styles. (Doctoral Dissertation, Miami Institute of Psychology of the Caribbean Center for Advanced Studies, 1999). Dissertation Abstracts International, 60(6-B), 3016. (UMI No. 9936128)

Green, R. J., Bettinger, M., \& Zacks, E. (1996). Are lesbian couples "fused" and gay male couples "disengaged?" Questioning gender straightjackets. In J. Laird \& R. J. Green (Eds.). Lesbians and gays in couples and families: A handbookfor therapists (pp. 185-230). San Francisco: Jossey-Bass Publishers, Inc. 
Green, R. J., \& Werner, P. D. (1996). Intrusiveness and closeness-caregiving: Rethinking the concept of family "enmeshment." Family Process, 35, 115-134.

Greene, K., Causby, V., \& Miller, D. H. (1999). The nature and function of fusion in the dynamics of lesbian relationships. Affilia, 1999, 78-97.

Greenfield, S., \& Thelen, M. (1997). Validation of the fear of intimacy scale with a lesbian and gay male population. Journal of Social and Personal Relationships, 14 (5), 707-716.

Griffin, D., \& Bartholomew, K. (1994). The metaphysics of measurement: The case of adult attachment. In K. Bartholomew \& D. Perlman (Eds.), Advances in personal relationships: Vol. 5. Attachment processes in adulthood (pp. 17-52). London: Jessica Kingsley.

Hazan, C., \& Shaver, P. (1987). Romantic love conceptualized as an attachment process. Journal of Personality and Social Psychology, 52, 511-524.

Hendrick, S. S. (1988). A generic measure of relationship satisfaction. Journal of Marriage and the Family, 50(1), 93-98.

Hendrick, S., Dicke, A., \& Hendrick, C. (1998). The relationship assessment scale. Journal of Social and Personal Relationships, 15(1), 137-142.

Hill, C. A. (1999). Fusion and conflict in lesbian relationships. Feminism and Psychology, 9, 179-185.

Hornstein, R. T. (1996). An exploration of women's attitudes towards closeness in intimate relationships. (Doctoral dissertation, Temple University, 1996). Dissertation Abstracts International, 57, 4089.

Igartua, K. J. (1998). Therapy with lesbian couples: The issues and the interventions. Canadian Journal of Psychiatry, 43, 391-396. 
Jordan, J. V., Kaplan, A. G., Miller, J. B, Stiver, I. P., \& Surrey, J. L. (1991). Women's growth in connection: Writings from the Stone Center. New York: Guilford.

Jordan, K. M., \& Deluty, R. H. (1998). Coming out for lesbian women: Its relations to anxiety, positive affectivity, self-esteem, and social support. Journal of Homosexuality, 35(2), 41-63.

Kahn, M. J. (1991). Factors affecting the coming out process for lesbians. Journal of Homosexuality, 21(3), 47-70.

Karpel, M. (1976). Individuation: From fusion to dialogue. Family Process, 15, 65-82.

Krestan, J., \& Bepko, C. S. (1980). The problem of fusion in the lesbian relationship. Family Process, 19, 277-289.

Krieger, S. (1983). The mirror dance-identity in a woman's community. Philadelphia: Temple University Press.

Kurdek, L. A., \& Schmitt, J. P. (1986). Early development of relationship quality in heterosexual married, heterosexual cohabiting, gay, and lesbian couples. Developmental Psychology, 22, 305-309.

Kurdek, L. A. (1988). Perceived social support in gays and lesbians in cohabiting relationships. Journal of Personality and Social Psychology, 54, 504-509.

Levitz-Jones, E. M., \& Orlofsky, J. L. (1985). Separation-individuation and intimacy capacity in college women. Journal of Personality and Social Psychology, 49 (1), $156-169$.

Lin, N. (1986). Conceptualizing social support. In N. Lin, A. Dean, \& W.M. Ensel (Eds.). Social support, life events, and depression. (pp. 17-30). Orlando, FL: Academic. Lindenbaum, J. (1985). The shattering of an illusion: The problem of competition in lesbian relationships. Feminist Studies, 11(1), 85-103. 
Mahler, M., Pine, F., \& Bergman, A. (1975). The psychological birth of the human infant. New York: Basic Books, Inc.

McBain, S. M. (2000). The role of fusion and patterns of attachment in the relationship satisfaction of lesbians. Dissertation Abstracts International, 60 (8), 4304B. (UMI No. 9940778)

McCandlish, D. (1985). Therapeutic issues with lesbian couples. Journal of Homosexuality, 7(1), 71-78.

Mencher, J. (1990). Intimacy in lesbian relationships: A critical re-examination of fusion. In Jordan (Eds.), Women's growth in diversity: More writings from the Stone Center (pp. 311-330). New York: Guilford.

Mencher, J., \& Slater, S. (1991). The lesbian family life cycle: A contextual approach. American Journal of Orthopsychiatry, 61, 372-382.

Miller (1991). The development of women's sense of self. In J. V. Jordan, A. G. Kaplan, J. B. Miller, I. P. Stiver \& J. L. Surrey (Eds.). Women's growth in connection: Writings from the Stone Center (pp. 11-26). New York: Guilford.

Minuchin, S. (1974). Families and family therapy. Cambridge: Harvard University Press. Murphy, B. C. (1989). Lesbian couples and their parents: The effects of perceived parental attitudes on the couple. Journal of Counseling and Development, 68, 46-51. Murphy, B. C. (1992). Counseling lesbian couples: Sexism, Heterosexism, and Homophobia. In S. H. Dworkin \& F. J. Gutierrez (Eds.), Counseling gay men \& lesbians: Journey to the end of the rainbow (pp.63-79). Alexandria, VA: American Association for Counseling and Development.

Olson, D. H., McCubbin, H. I., Barnes, H., Larsen, M., Muxen, M., \& Wilson, M. (1983). Families: What makes them work. Beverly Hills, CA: Sage Publications. 
Olson, D. H. (1986). Circumplex Model VII: Validation studies and FACES III. Family Process, 25, 337-351.

Olson, M. E. (1988). Factors related to the psychological well-being of lesbian women. (Doctoral Dissertation, California School of Professional Psychology, 1988). Dissertation Abstracts International, 49, 4553.

Olson, D. H. (1993). Circumplex Model of marital and family systems: Assessing family functioning. In F. Walsh (Ed.). Normal family processes (2nd ed.) (pp. 104-137). New York: Guilford Press.

Pardie, L., \& Herb, C. R. (1997). Merger and fusion in lesbian relationships: A problem of diagnosing what's wrong in terms of what's right. Women \& Therapy, 20, $51-61$.

Patterson, C. J. (1994). Children of the lesbian baby boom: Behavioural adjustment, selfconcepts, and sex-role identity. In B. Greene \& M. Herek (Eds.), Lesbian and gay psychology: Theory, research and clinical application (pp. 156-175). Thousand Oaks, CA: Sage Publications.

Pearlman, S. (1989). Distancing and connectedness: Impact on couples formation in lesbian relationships. Women \& Therapy, 9(3), 77-88.

Peplau, L. A., Cochran, S., Rook, K., \& Padesky, C. (1978). Loving women: Attachment and autonomy in lesbian relationships. Journal of Social Issues, 34(3), 7-27.

Roper, K. (1997). Lesbian couple dynamics and individual's psychological adjustment. Dissertation Abstracts International, 58 (5), 2698B. (UMI No. 9734318)

Schreurs, K. M. G., \& Buunk, B. P. (1995). Intimacy, autonomy and relationship satisfaction in Dutch lesbian couples and heterosexual couples. Journal of Psychology and Human Sexuality, 7(4), 41-57. 
Schreurs, K. M. G., \& Buunk, B. P. (1996). Closeness, autonomy, equity, and relationship satisfaction in lesbian couples. Psychology of Women Quarterly, 20, $577-592$.

Senchak, M., \& Leonard, K. E. (1992). Attachment styles and marital adjustment among newlywed couples. Journal of Social and Personal Relationships, 9, 51-64.

Sharpsteen, D. J., \& Kirkpatrick, L. A. (1997). Romantic jealousy and adult romantic attachment. Journal of Personality and Social Psychology, 72, 627-640.

Simpson, J. A. (1990). Influence of attachment styles on romantic relationships. Journal of Personality and Social Psychology, 59, 971-980.

Statistics Canada. (2001). Population by selected ethnic origins, by provinces and territories (Ontario), 2001 Census [Data file]. Available from Statistics Canada Web site, http://www.statcan.ca

Strahan, B. J. (1991). Attachment theory and family functioning: Expectancies and congruencies. Australian Journal of Marriage and Family, 12, 12-26.

Surrey, J. L. (1991). The "self-in-relation": A theory of women's development. In J. V. Jordan, A. G. Kaplan, J. B. Miller, I. P. Stiver \& J. L. Surrey (Eds.). Women's growth in connection: Writings from the Stone Center (pp. 11-26). New York: Guilford.

Tordoski, J. (1995). Attachment and divorce: A therapeutic view. Journal of Divorce and Remarriage, 22, 189-204.

Wayment, H. A., \& Peplau, L. A. (1995). Social support and well-being among lesbian and heterosexual women: A structural modeling approach. Personality and Social Psychology Bulletin, 21(11), 1189-1199.

Weiss, R. S. (1974). The provisions of social relationships. In Z. Rubin (Ed.). Doing unto others (pp. 17-26). Englewood Cliffs, N. J.: Prentice Hall. 
Werner, P. D., \& Green, R. -J. (1999). California Inventory for Family Assessment (CIFA). Manual for the second research edition. Retrieved December 8, 2003, from http://ourworld.compuserve.com/homepages/pdwerner/cifa2-I.htm.

Werner, P. D., Green, R. -J., Greenberg, J., Browne, T. L., \& McKenna, T. E. (2001). Beyond "enmeshment:" Evidence for the independence of intrusiveness and closeness-caregiving in married couples. Journal of Marital and Family Therapy, 27, 459-471.

Zacks, E., Green, R. J., \& Marrow, J. (1988). Comparing lesbian and heterosexual couples on the Circumplex Model: An initial investigation. Family Process, 27, 471484.

Zimet, G. D., Dahlem, N. W., Zimet, S. G., \& Farley, G. K. (1988). The Multidimensional Scale of Perceived Support. Journal of Personality Assessment, 52, 30-41. 
Appendix A

Bartholomew's (1990) Adult Attachment Typology

Model of Self

Positive

Negative

\begin{tabular}{|l|c|c|}
\multicolumn{1}{l|}{\begin{tabular}{l|l} 
Positive \\
Model of \\
Other \\
$\quad$ Negative
\end{tabular}} & Secure & Preoccupied \\
\cline { 2 - 3 } & Dismissing & Fearful \\
\hline
\end{tabular}


Appendix B

Flyer Advertisement

Relationship Study

Are you a woman who is CURRENTLY in a monogamous relationship with a woman, for AT LEAST 3 MONTHS?

Are you 18 years or older?

$\mathrm{Hi}$, my name is Salma and I am a lesbian Psychology graduate student at the University of Windsor, Ontario.

If you meet ALL of the above criteria, and you are excited about participating in psychological research, then you qualify for my study of the relationship dynamics of lesbian couples.

If you are interested in helping me with this study, please call me at (519) 253-3000 ext.2256, or email me at salma_relationships@yahoo.ca.

Please leave a message, telling me that you are interested in taking part in my research. Don't forget to also tell me your FULL NAME and ADDRESS! I will mail you a package of questionnaires, with complete instructions on filling them out, and returning them to me, at no cost to you.

If you have any further questions about my research, feel free to also leave your phone number or email address, and I will be happy to get back to you.

And don't worry, once you have completed and returned the questionnaires, you will not be identified in any way with the information you provide.

THANK YOU for the time you took to read this! I very much look forward to hearing from you! 
Appendix E

Letter of Information

The Relationship Dynamics of Lesbian Couples

Please read this page so that you know what this study is about and what you are being asked to do. It is our responsibility to make sure that you are familiar with the general nature of the study, and that you understand the risks and benefits associated with participating in this study. In this way, you can decide in a free and informed manner, whether you want to participate or not. By filling out these questionnaires and returning them anonymously in the self-addressed envelope, you are indicating that you know about the study and that you agree to participate.

This research study is being conducted by Salma Ackbar, a graduate student in the Department of Psychology at the University of Windsor, under the supervision of Dr. Charlene Senn, a professor at the same institution. The study is being done to fulfill the requirements of an M.A. thesis. This study will examine the dynamics of lesbian relationships. If you volunteer to participate in this study, you will be asked to fill out a number of questionnaires, which should take you about 30-40 minutes to complete altogether. In order to take part in this study, you need to be 18 years or older, and currently be in a romantic relationship with a woman, for at least 3 months.

If you decide not to participate in this study, we ask that you pass the unanswered questionnaire onto another woman, whom you know is currently in a lesbian relationship, and has been so for at least 3 months. If there is no one for you to pass it on to, we ask that you please return the entire questionnaire package back to us. This is important because we need to maintain confidentiality of the questionnaires, and to know exactly how many women agree to participate.

The questions in the surveys are personal questions about your relationship, your partner, and your own thoughts and behaviour. If you feel uncomfortable about answering any of the questions, you are free to not answer those questions or to not return the questionnaires. There is also a list of community resources that you can use, should you decide you want to seek support or help of some kind, as a result of completing the questionnaires. Your answers to all the questions and your participation in general however, are greatly appreciated. Your answers will contribute to a growing and interesting research literature on lesbian relationships, carried out by researchers from our community. Your questionnaire package contains a token of our appreciation for the time and effort you spend in completing the questionnaires.

If you agree to participate, your responses will be completely anonymous. The questionnaires have no identifying marks on them, and you should not put your name on any of the questionnaires. Any identifying information you provide us on the postcard will be mailed back separately from your questionnaires, so that we will not be able tell who answered which questionnaires. 
All the data will be kept in a locked filing cabinet, in a locked office to which only the researcher and her supervisor will have access. When the data are no longer needed, they will be destroyed. Some of the raw data will be released to Dr. Paul Werner at the California School of Professional Psychology of Alliant International University. Dr. Werner designed one of the surveys we are using, and wants a copy of the data for recordkeeping purposes only. Again, the data we supply him will have no identifying information.

Your participation is voluntary. You may refuse to answer any of the questions and you can stop responding at any point. You can also choose not to return the questionnaires to the researcher. Please keep our token regardless of whether you decide to participate or not, as our thanks for being interested in the study.

You can request feedback of the results of the study. To do this, please ensure you indicate your mailing address and whether or not you would like feedback, on the small postcard included in the package. Please make sure you return this postcard to the researcher separately from the rest of the questionnaire package. The reason for doing this is, so that we cannot link your name to your questionnaires. If you request feedback, it will be mailed to you upon completion of the study, which is expected to be by the fall of 2005 .

This study has been reviewed and received ethics clearance through the University of Windsor Research Ethics Board. If you have any questions or concerns about the research, please feel free to contact Salma Ackbar or Dr. Charlene Senn at (519- 2533000 ext. 2256). If you have questions regarding your rights as a research subject, contact:

Research Ethics Coordinator

Telephone: 519-253-3000 ext. 3916

University of Windsor

Email: ethics@uwindsor.ca

Windsor, Ontario

N9B 3P4

These are the terms under which I will conduct research.

Salma Ackbar

Date

(Prinicipal Researcher)

I have read this letter and understand its content.

I agree to participate (begin the questionnaire)

I decline to participate (Stop here, and mail it back in the pre-paid envelope, or pass on to a friend 


\author{
Appendix F \\ Community Resources for Lesbian and Bisexual Women
}

\title{
Toronto
}

1) The 519 Church Street Community Centre

Programs offered: Support groups, social groups, free counselling, community living, legal services, children's services and many more.

For more information, contact: info@the519.org or call (416) 392-6874

Or visit: www.the519.org

Address: 519 Church Street

Toronto, ON

M4Y 2C9

2) Sherbourne Health Centre

Offers comprehensive health care to gay, lesbian and bisexual communities, including free counselling for individuals, couples and families; support groups, and employment opportunities.

For more information, contact: info@sherbourne.on.ca or call (416) 324-4180

Or visit: www.sherbourne.on.ca

Address: 333 Sherbourne Street

Toronto, ON

M5A 2S5

\section{3) Supporting Our Youth}

A community program designed to improve the lives of lesbian, gay, bisexual, transsexual and transgendered youth in Toronto through active involvement in the community. Also provides employment opportunities and support services; offers free counselling to youth under the age of 25 .

For more information, contact: soy@soytoronto.org or call (416) 924-2100 ext. 264

Or visit: www.soytoronto.org

Address: c/o CTYS

65 Wellesley Street East

Suite 300

Toronto, ON

M4Y 1G7

4) Lesbian Gay Bi Youth Line

Provides peer support and information services to youth who may identify as 
lesbian, gay, bisexual, two-spirited, and transgendered.

Telephone: (416) 962-YOUTH

Toll Free: 1-800-268-YOUTH

\section{5) Coming Out/Being Out Discussion Group}

Offers an informal, non-judgmental environment for lesbian, gay, bisexual, twospirited, transsexual, transgendered, and questioning persons between 20 and 40 years of age, who are at all stages of coming and being out. People meet weekly to discuss issues that concern them.

For more information, contact: comingoutbeingout@hotmail.com

Or visit: http://www.geocities.com/comingoutbeingout/index.html

6) Distress Centres of Toronto

Anonymous, confidential telephone service, providing crisis intervention, emotional support and referrals to people living in Toronto. Open 24 hours, 7 days a week.

For more information, or to talk, call: (416) 408-HELP

Or visit: www.torontodistresscentre.com

7) David Kelley Lesbian and Gay Community Counselling Program

Provides professional, short-term, individual, couple and family counselling to lesbians, gay men and related communities

To obtain counselling services call: (416) 595-9618 or email: sau@fsatoronto.com

To find out more information about this service, visit:

http://www.fsatoronto.com/programs/fsaprograms/davidkelley.html

Or email: dks@fsatoronto.com

\section{Windsor}

1) Out on Campus

A University of Windsor student group

For more information, contact: outoncampus@gaywindsor.com

2) Womyn Out

Support group open to lesbian and lesbian-friendly women. 
For more information, contact: womynout@free2marry.com

3) Sandwich Community Health Centre

Offers free counselling, and variety of other services

For more information, contact: schc@wincom.net or call: (519) 258-6002

Address: Sandwich P/O Box 7391

Windsor, Ontario N9C 4E9

4) Lesbian Gay Bi Youth Line

Provides peer support and information services to youth who may identify as lesbian, gay, bisexual, two-spirited, and transgendered.

Telephone: (416) 962-YOUTH

Toll Free: 1-800-268-YOUTH

5) Distress Centre of Windsor

Anonymous, confidential telephone service, providing crisis intervention, emotional support and referrals to people in Windsor and surrounding area.

For more information, or to talk, call: (519) 256-5000

Or visit: www.dcwindsor.com

6) Hiatus House

Call: (519) 252-7781 or 1-800-265-5142

7) Sexual Assault Crisis Centre of Essex County

Provides 24-hour, seven days per week, free, anonymous crisis/support telephone line; individual and group counselling; information on the Criminal Law System; information and referral; community outreach to women from diverse ethno-cultural and multi-racial communities; and much more.

Call the Crisis Line: (519) 253-9667 or contact: sacc@wincom.net

Or visit: www.sacha.on.ca

\section{Other (across Ontario)}

1) Assaulted Women's Helpline

This service is available 24 hours a day, 7 days a week. It offers crisis, counselling and referrals for women needing a shelter, legal advice or other supports. This service is free and offered in over 100 languages. 
Call Toll Free: 1-866-863-0511

Or for more information call: 1-866-863-7868

Or visit: http://www.awhl.org

2) Distress Centres Ontario

To find a distress centre near you, visit: www.dcontario.org Or check your local telephone directory 


\section{Appendix H}

\section{Experiences in Close Relationships Inventory}

The following statements concern how you feel in romantic relationships. We are interested in how you generally experience relationships, not just what is happening in a current relationship. Respond to each statement by indicating how much you agree or disagree with it. Write the number in the space provided, using the following rating scale.

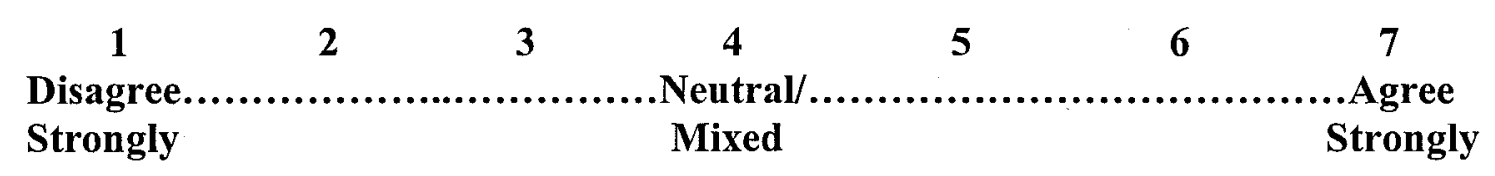

1. I prefer not to show a partner how I feel deep down.

2. I worry about being abandoned.

3. I am very comfortable being close to romantic partners. (R)

4. I worry a lot about my relationship.

5. Just when my partner starts to get close to me I find myself pulling away.

6. I worry that romantic partners won't care about me as much as I care about them.

-7. I get uncomfortable when a romantic partner wants to be very close.

- 8. I worry a fair amount about losing my partner.

- 9. I don't feel comfortable opening up to romantic partners.

- 10. I often wish that my partner's feelings for me were as strong as my feelings for her.

11. I want to get close to my partner but I keep pulling back.

— 12. I often want to merge completely with romantic partners, and this sometimes scares them away.

- 13. I am nervous when partners get too close to me.

- 14. I worry about being alone.

- 15. I feel comfortable sharing my private thoughts and feelings with my partner. (R)

- 16. My desire to be very close sometimes scares people away.

- 17. I try to avoid getting too close to my partner. 
$\begin{array}{lllllll}1 & 2 & 3 & 4 & 5 & 6 & 7\end{array}$

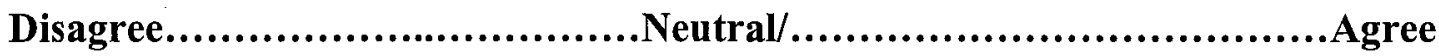

$\begin{array}{lll}\text { Strongly } & \text { Mixed } & \text { Strongly }\end{array}$

18. I need a lot of reassurance that I am loved by my partner.

19. I find it relatively easy to get close to my partner. (R)

20. Sometimes I feel that I force my partners to show more feeling, more commitment.

21. I find it difficult to allow myself to depend on romantic partners.

22. I do not often worry about being abandoned. (R)

23. I prefer not to be close to romantic partners.

24. If I can't get my partner to show interest in me, I get upset or angry.

25. I tell my partner just about everything. (R)

26. I find that my partner(s) don't want to get as close as I would like.

_ 27. I usually discuss my problems and concerns with my partner. (R)

- 28. When I'm not involved in a relationship, I feel somewhat anxious and insecure.

-29. I feel comfortable depending on romantic partners. (R)

- 30. I get frustrated when my partner is not around as much as I would like.

- 31. I don't mind asking romantic partners for comfort, advice, or help. (R)

- 32. I get frustrated if romantic partners are not available when I need them.

- 33. It helps to turn to my romantic partner in times of need. (R)

— 34. When romantic partners disapprove of me, I feel really bad about myself.

- 35. I turn to my partner for many things, including comfort and reassurance. (R)

-36. I resent it when my partner spends time away from me.

Note: $\mathrm{R}=$ Reverse scored for final scale score 


\section{Appendix I}

\section{Multidimensional Scale of Perceived Social Support}

We are interested in how you feel about the following statements. Read each statement carefully. Indicate how you feel about each statement.

\begin{tabular}{|c|c|c|c|c|c|c|c|}
\hline & 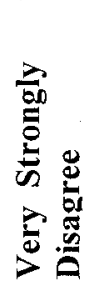 & 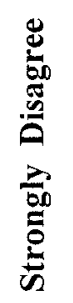 & 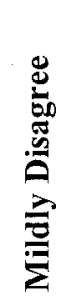 & $\begin{array}{l}\overline{\bar{E}} \\
\bar{E} \\
\bar{E}\end{array}$ & 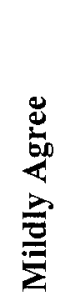 & 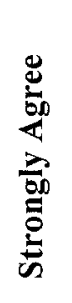 & 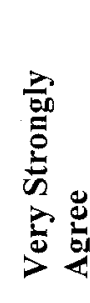 \\
\hline $\begin{array}{l}\text { 1. There is a special person who is around } \\
\text { when I am in need. }\end{array}$ & 1 & 2 & 3 & 4 & 5 & 6 & 7 \\
\hline $\begin{array}{l}\text { 2. There is a special person with whom } \\
\text { I can share my joys and sorrows. }\end{array}$ & 1 & 2 & 3 & 4 & 5 & 6 & 7 \\
\hline 3. My family really tries to help me. & 1 & 2 & 3 & 4 & 5 & 6 & 7 \\
\hline $\begin{array}{l}\text { 4. I get the emotional help and support I } \\
\text { need from my family. }\end{array}$ & 1 & 2 & 3 & 4 & 5 & 6 & 7 \\
\hline $\begin{array}{l}\text { 5. I have a special person who is a real source } \\
\text { of comfort to me. }\end{array}$ & 1 & 2 & 3 & 4 & 5 & 6 & 7 \\
\hline 6. My friends really try to help me. & 1 & 2 & 3 & 4 & 5 & 6 & 7 \\
\hline $\begin{array}{l}\text { 7. I can count on my friends when things } \\
\text { go wrong. }\end{array}$ & 1 & 2 & 3 & 4 & 5 & 6 & 7 \\
\hline $\begin{array}{l}\text { 8. I can talk about my problems with my } \\
\text { family. }\end{array}$ & 1 & 2 & 3 & 4 & 5 & 6 & 7 \\
\hline $\begin{array}{l}\text { 9. I have friends with whom I can share my } \\
\text { joys and sorrows. }\end{array}$ & 1 & 2 & 3 & 4 & 5 & 6 & 7 \\
\hline $\begin{array}{l}\text { 10. There is a special person in my life who } \\
\text { cares about my feelings. }\end{array}$ & 1 & 2 & 3 & 4 & 5 & 6 & 7 \\
\hline $\begin{array}{l}\text { 11. My family is willing to help me make } \\
\text { decisions }\end{array}$ & 1 & 2 & 3 & 4 & 5 & 6 & 7 \\
\hline $\begin{array}{l}\text { 12. I can talk about my problems with my } \\
\text { friends. }\end{array}$ & 1 & 2 & 3 & 4 & 5 & 6 & 7 \\
\hline
\end{tabular}




\section{Appendix J}

\section{Network Sector Closeting Measure}

In this section you are asked to respond to a variety of questions with respect to five different groups of people (your immediate family, your extended family, your friends that are heterosexual or "straight", your friends that are lesbian, gay, or bisexual, and your co-workers or people in your workplace). Please indicate your level of agreement with each statement for each of the five different groups by circling the number that corresponds to your choice.

1. The people in (group from below) know that I am a lesbian.

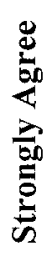

\begin{tabular}{|l|c|c|c|c|c|c|c|c|c|}
\hline $\begin{array}{l}\text { My immediate family (mother, father, } \\
\text { siblings) }\end{array}$ & 1 & 2 & 3 & 4 & 5 & 6 & 7 & 8 & 9 \\
\hline My extended family (aunts, uncles, etc.) & 1 & 2 & 3 & 4 & 5 & 6 & 7 & 8 & 9 \\
\hline My straight (heterosexual) friends & 1 & 2 & 3 & 4 & 5 & 6 & 7 & 8 & 9 \\
\hline My lesbian, gay, or bisexual friends & 1 & 2 & 3 & 4 & 5 & 6 & 7 & 8 & 9 \\
\hline My co-workers & 1 & 2 & 3 & 4 & 5 & 6 & 7 & 8 & 9 \\
\hline
\end{tabular}

2. Those that know I am a lesbian are supportive of this.

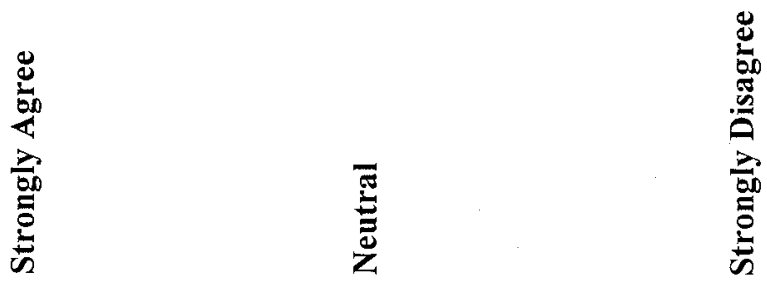

\begin{tabular}{|l|l|l|l|l|l|l|l|l|l|}
\hline My immediate family & 1 & 2 & 3 & 4 & 5 & 6 & 7 & 8 & 9 \\
\hline My extended family & 1 & 2 & 3 & 4 & 5 & 6 & 7 & 8 & 9 \\
\hline My straight (heterosexual) friends & 1 & 2 & 3 & 4 & 5 & 6 & 7 & 8 & 9 \\
\hline My lesbian, gay, or bisexual friends & 1 & 2 & 3 & 4 & 5 & 6 & 7 & 8 & 9 \\
\hline My co-workers & 1 & 2 & 3 & 4 & 5 & 6 & 7 & 8 & 9 \\
\hline
\end{tabular}


3. I do not feel comfortable expressing affection to my partner in front of....

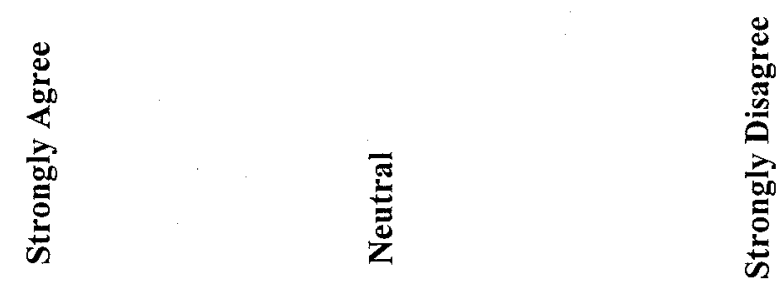

\begin{tabular}{|l|c|c|c|c|c|c|c|c|c|}
\hline My immediate family & 1 & 2 & 3 & 4 & 5 & 6 & 7 & 8 & 9 \\
\hline My extended family & 1 & 2 & 3 & 4 & 5 & 6 & 7 & 8 & 9 \\
\hline My straight (heterosexual) friends & 1 & 2 & 3 & 4 & 5 & 6 & 7 & 8 & 9 \\
\hline My lesbian, gay, or bisexual friends & 1 & 2 & 3 & 4 & 5 & 6 & 7 & 8 & 9 \\
\hline My co-workers & 1 & 2 & 3 & 4 & 5 & 6 & 7 & 8 & 9 \\
\hline
\end{tabular}

4. When I am invited to a social gathering (dinner, holidays, movies, etc.) they invite my partner as well.

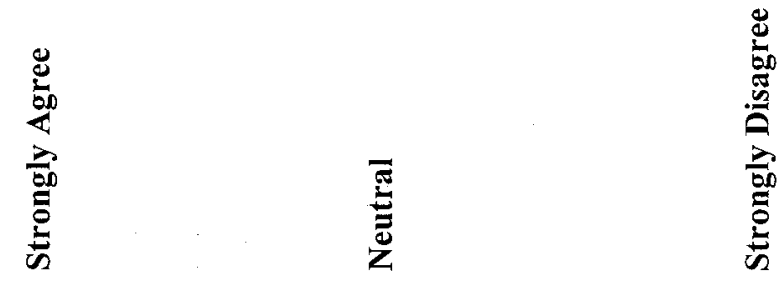

\begin{tabular}{|l|l|l|l|l|l|l|l|l|l|}
\hline My immediate family & 1 & 2 & 3 & 4 & 5 & 6 & 7 & 8 & 9 \\
\hline My extended family & 1 & 2 & 3 & 4 & 5 & 6 & 7 & 8 & 9 \\
\hline My straight (heterosexual) friends & 1 & 2 & 3 & 4 & 5 & 6 & 7 & 8 & 9 \\
\hline My lesbian, gay, or bisexual friends & 1 & 2 & 3 & 4 & 5 & 6 & 7 & 8 & 9 \\
\hline My co-workers & 1 & 2 & 3 & 4 & 5 & 6 & 7 & 8 & 9 \\
\hline
\end{tabular}


Appendix K

Relationship Assessment Scale

1. How well does your partner meet your needs?
A
B
C
D
E

Poorly

Average

Extremely Well

2. In general, how satisfied are you with your relationship?
A
B
C
D
E
Average
Extremely Satisfied

Unsatisfied

3. How good is your relationship compared to most?
A
B
C
D
E
Poor
Average
Excellent

4. How often do you wish you hadn't gotten into this relationship?
A
B
C
D
E
Average
Very Often

Never

5. To what extent has your relationship met your original expectations?
A
B
$\mathrm{C}$
D
E

Hardly

Average

Completely

At all

6. How much do you love your partner?
A
B
C
D
E
Average
Very Much

Not much

7. How many problems are there in your relationship?
A
B
C
D
E
Very Few
Average
Very Many 
Appendix L

Demographic Information Questionnaire

The following questionnaire will provide us with more information about how women's background characteristics relate to their romantic relationships.

Please answer the following items for yourself

1. Age:

2. Ethnicity/Race:

Caucasian

Asian

Aboriginal

West Indian
African/Black

East Indian

Arabic/Middle Eastern Other (please specify)

Multiracial (please specify)

3. Sexual Orientation:

4. Place of Residence: City

Province

5. Religious/Spiritual Identification (if any):

6. Last completed level of education:

7. What is your current occupation:

8. If you are not currently working, what/who is the major source of your major income?

9. What is your approximate yearly income level before taxes? 

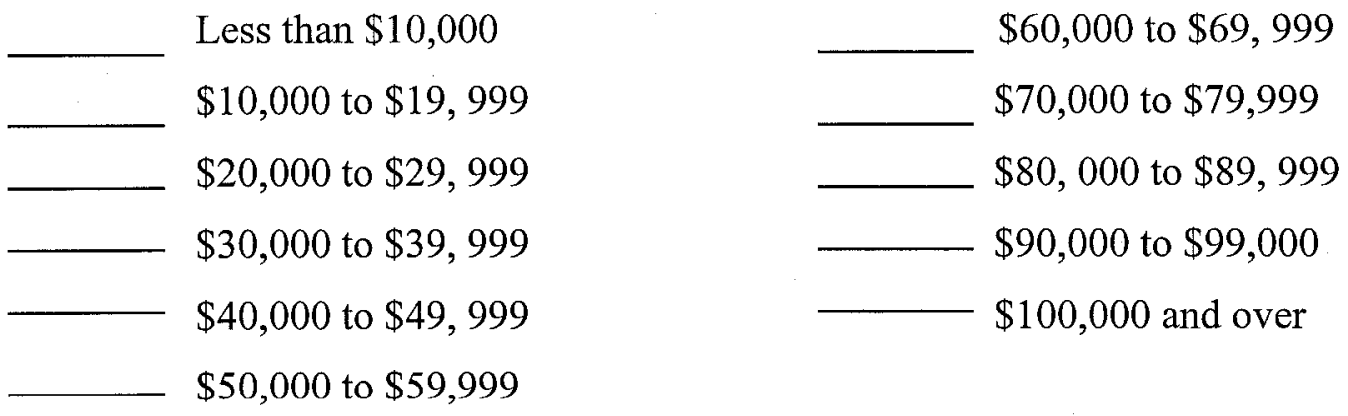

10. Are you currently in a romantic relationship with a woman?

Yes

No

(If no, please do not complete the questionnaires. Mail back the package if possible)

11. How long have you been in your current relationship?

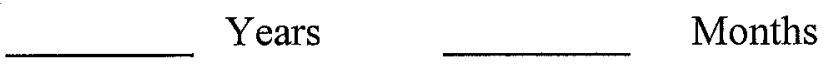

12. Do you live with your current partner? _ _ Yes _ N No

13. If you live with your partner, do you live with your children also?

Yes $\quad$ No

14. If you do not live with your current partner, whom do you live with?
Live Alone
_ Live with Children
Live with Roommate
Live with Friend/s
Live with Parents/Relatives
Other (please specify) 
15. Do you have any children?

Yes No

16. If so, how many children do you have?

17. Are your children: Biological Adopted Step-children

18. If you have children, are they from your current relationship, or a previous one?

19. Are you currently in (mark all that apply):

$\begin{array}{ll}\text { Couples Therapy } & \text { Individual Therapy } \\ \text { Group Therapy } & \quad \text { Other (please specify) } \\ & \text { No Therapy }\end{array}$

20. If you are in therapy, is it for (mark all that apply):

Relationship Issues

Personal Issues

Other (please specify)

21. How did you hear about this study? 
Please answer the following questions for your partner

What is your partner's...

1. Age:

2. Ethnicity/Race:

Caucasian

$\begin{array}{ll}\longleftarrow & \text { Asian } \\ & \text { Aboriginal } \\ & \text { West Indian }\end{array}$

African/Black

East Indian

Arabic/Middle Eastern

Other (please specify)

\section{Multiracial (please specify)}

3. Sexual Orientation:

4. Place of Residence: City

Province

5. Religious/Spiritual Identification (if any):

6. Last completed level of education:

7. Current occupation:

8. What is your approximate yearly income level before taxes?

Less than $\$ 10,000$

$\$ 10,000$ to $\$ 19,999$

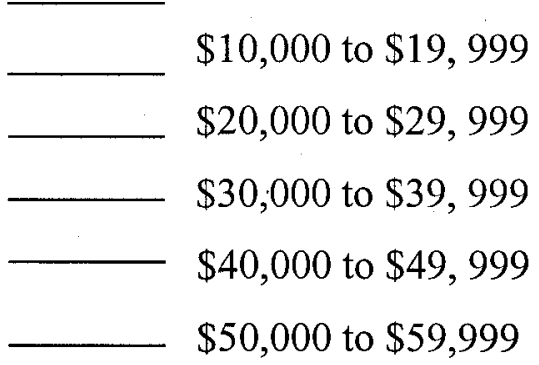

$\$ 60,000$ to $\$ 69,999$

$\$ 70,000$ to $\$ 79,999$

$\$ 80,000$ to $\$ 89,999$

$\$ 90,000$ to $\$ 99,000$

$\$ 100,000$ and over

Don't know 


\section{VITA AUCTORIS}

Salma Ackbar was born in 1978 in Trinidad \& Tobago. She graduated from St. Joseph's Convent (Port of Spain, Trinidad) in 1997. In 2002, she obtained a B. A. (Honours) in Psychology from Queen's University, Kingston, Ontario. She completed her M. A. in child clinical psychology at the University of Windsor, Ontario, in 2005. She currently is enrolled in the child clinical psychology $\mathrm{Ph}$. D. program at the University of Windsor. 